\title{
The AUTUMNX magnetometer meridian chain in Québec, Canada
}

\author{
Martin Connors ${ }^{1 *}$, lan Schofield ${ }^{1}$, Kyle Reiter ${ }^{1}$, Peter J. Chi ${ }^{2}$, Kathryn M. Rowe ${ }^{2}$ and Christopher T. Russell ${ }^{2}$
}

\begin{abstract}
The AUTUMNX magnetometer array consists of 10 THEMIS-class ground-based magnetometers deployed to form a meridian chain on the eastern coast of Hudson Bay in eastern Canada, a second partial chain one hour of magnetic local time further east, and one magnetometer at an intermediate midlatitude site. These instruments, augmented by those of other arrays, permit good latitudinal coverage through the auroral zone on two meridians, some midlatitude coverage, and detection of magnetic field changes near the sensitive infrastructure of the Hydro-Québec power grid. Further, they offer the possibility for conjugate studies with Antarctica and the GOES East geosynchronous satellite, and complement the Chinese International Space Weather Meridian Circle Program. We examine current world distribution of magnetometers to show the need for AUTUMNX, and describe the instrumentation which allows near-real-time monitoring. We present magnetic inversion results for the disturbed day February 17, 2015, which showed classic signatures of the substorm current wedge, and developed into steady magnetospheric convection (SMC). For a separate event later that day, we examine a large and rapid magnetic field change event associated with an unusual near-Earth transient. We show GOES East conjugacy for these events.
\end{abstract}

Keywords: Geomagnetism, Geophysical instrumentation, Geomagnetically induced currents, Substorm, Electrojet, Data inversion

\section{Introduction}

In the mid eighteenth century, Hiorter, in Scandinavia, established in a scientific way that there was a connection between changes in magnetic fields and the aurora (Potemra 1985; Chapman and Bartels 1940) (and references therein). Systematic observations of the magnetic field of the Earth, largely driven by the rise of worldwide navigation, greatly increased in the eighteenth century (Jackson 1992). Networks of ground-based magnetic observatories were established in the early nineteenth century largely at the instigation of von Humboldt and Gauss, the latter of whom added the ability to measure field strength and mathematically interpret distributed observations (Stern 2002). Observations were already made along what would now be termed a meridian chain, a set of observatories arrayed north-south, in 1836 (Soffel 2015). Due to the presence of these observatories, the Carrington event of 1859 could be well recorded by

*Correspondence: martinc@athabascau.ca

${ }^{1}$ Athabasca University Observatories, 1 University Drive, Athabasca, AB T9S 3A3, Canada

Full list of author information is available at the end of the article magnetic measuring devices. This event produced aurora extending to tropical latitudes, and was clearly associated with unusual solar activity. Nevertheless, the concept of solar-terrestrial relations took at least a half century more to establish (Cliver 1859 to 2005). In the early twentieth century, Birkeland (1908) established observatories in Scandinavia to observe both the aurora and its magnetic field. Systematic study of auroras during and after the International Geophysical year of 1957 (Akasofu 1964) established that they are usually arrayed east-west in magnetic coordinates, and delineate the auroral oval, which also has this orientation. Ionospheric currents within the oval flowing primarily in the east-west direction produce magnetic perturbations perpendicular to it, in the northsouth and vertical directions. Much information can be learned about such currents by profiling perpendicular to them, i.e. in a magnetic meridian. Thus, meridian chains of magnetometers in the auroral zone are valuable for quantitative study of currents associated with aurora. In what follows we will regard a "magnetometer" as an instrument responding primarily to geomagnetic variations at frequencies of less than $10 \mathrm{~Hz}$.

\section{Springer}

(c) 2015 Connors et al. Open Access This article is distributed under the terms of the Creative Commons Attribution 4.0 International License (http://creativecommons.org/licenses/by/4.0/), which permits unrestricted use, distribution, and reproduction in any medium, provided you give appropriate credit to the original author(s) and the source, provide a link to the Creative Commons license, and indicate if changes were made. 
AUTUMNX (AUTUMN eXtension) is a magnetometer network established in late 2014 with the support of the Canadian Space Agency, in eastern Canada in the province of Québec, a region of North America in which previously magnetometers were sparse. AUTUMNX is operationally an eastward extension of the existing western Canadian AUTUMN magnetometer network established by Athabasca University and UCLA in 2003, although physically separated, being approximately 2000 $\mathrm{km}$ to the east within the large Canadian landmass. AUTUMN is an acronym for "Athabasca University THEMIS UCLA Magnetometer Network" indicating the partners (UCLA being the University of California, Los Angeles) and the intent to contribute to the THEMIS (Time History of Events and Macroscale Interactions during Substorms) space research mission (Angelopoulos 2008). The original AUTUMN array was deployed widely in western Canada around a central base in the province of Alberta, as shown in Fig. 1 and Table 1. Associated with the AUTUMN project, very low cost magnetometers were developed (Schofield et al. 2012) in hopes of making the array more extensive and denser. These have not yet seen permanent deployment and are not indicated here. In this region there are also numerous instruments of the CARISMA (Canadian Array for Realtime Investigations of Magnetic Activity) array (Mann et al. 2008) and of the former STEP (Solar-Terrestrial Energy Program) Polar Network run by K. Hayashi. We also indicate in Fig. 1 the location of the Meanook observatory of Natural Resources Canada (NRCan), which is located near the town of Athabasca. For reasons which may be historic, cultural, and in no small measure related to the difficult terrain, the eastern part of Canada, dominated in the auroral zone by the province of Québec, has had little coverage by modern ground-based space science instrumentation. AUTUMNX has remedied that situation in regard to magnetic measurements, and we proceed to place it in context. We then examine the instrumentation advances which have enabled the reliable operation of the new array, and the possibilities it offers for ground conjugate studies with Antarctica. Finally, we present recent science and space weather studies in which AUTUMNX allows unique insight.

\section{Status of magnetic instrumentation and need for AUTUMNX}

Figure 2 shows in its upper panel in black the locations of most of the 347 magnetometers in the northern hemisphere listed by SuperMAG (Gjerloev 2009; 2012) in 2015 (a current version of this list is available at http:// supermag.jhuapl.edu/mag/?tab=stationinfo after registration). The 10 new stations of AUTUMNX contribute to SuperMAG, but it is not a real-time service, and data has not appeared there as of this writing. AUTUMNX stations are shown in red in Fig. 2. The lower panel of Fig. 2 shows most of the 101 SuperMAG magnetometers in the southern hemisphere. The term "most" is used since the projection (orthographic from above the magnetic pole) may not show near-equatorial stations, which are few in number, in the dominant hemisphere shown. We note that not all of the instruments are still in operation. In Antarctica in particular, campaigns have temporarily installed magnetometers which once contributed, but no longer do. As a concrete example, the SuperMAG website (http://supermag.jhuapl.edu) had a total of 204 magnetometers with data available on Feb 24 2010, out of the nominal 448 listed, with only 29 south of the equator. We can nevertheless discuss aspects of the placement of magnetometers based on these maps, as part of the reason AUTUMNX came to have its present form.

The presence in Fig. 2 of several chains of magnetometers arrayed roughly north-south shows that this configuration has been desired by researchers. Indeed, we mentioned above the earliest north-south chain being established in 1836, although at what we now regard as subauroral latitudes (Soffel 2015). The longest such chain is McMAC (Mid-Continent Magnetoseismic Chain) bisecting North America (Chi et al. 2013), which consists mainly of the CARISMA array stations in that meridian north of the Canadian border, and UCLA and IGPPLANL instruments in the USA and Mexico. Roughly 20 degrees west of this chain is one made up mainly of AUTUMN and CARISMA stations. In Alaska a chain of magnetometers traverses the state, most being maintained by the University of Alaska. Sixty degrees further west (but now in the eastern hemisphere) is the 210 meridian chain of the Kyushu University (Yumoto 1996). These instruments are concentrated in Japan and on smaller Pacific Islands, with a few in the Russian auroral zone. Proceeding westward, the density of magnetometers rises greatly in Scandinavia, and several there form a chain (IMAGE) which includes the islands to the north of the European landmass (Tanskanen 2009). The coasts of Greenland house many magnetometers, and (see below) along its west coast these are well arrayed in a single magnetic meridian. This finally brings us back to North America, where a chain at about 70 degrees west is formed by two AUTUMNX instruments with other instruments (run by NRCan and MACCS of Augsburg College), and finally the well populated AUTUMNX East Hudson Bay (EHB) chain, complemented by NRCan station Sanikiluaq (on Belcher Island in Hudson Bay), and the MACCS station Cape Dorset on Baffin Island immediately north of AUTUMNX. We proceed to a similar description for the southern hemisphere, and return to a global discussion using geomagnetic coordinates. 


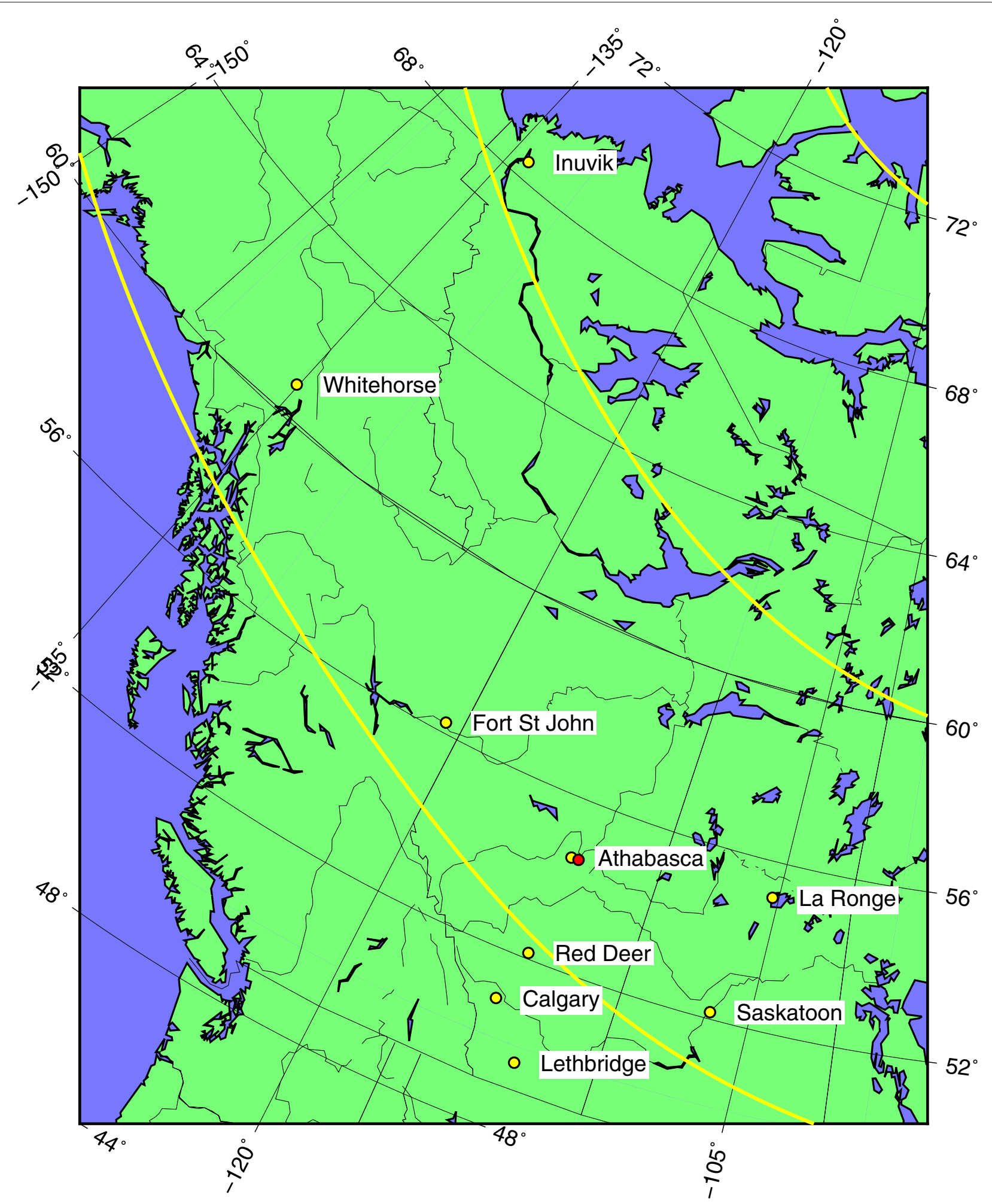

Fig. 1 The AUTUMN magnetometer array in western Canada. AUTUMN stations are indicated with a yellow dot. NRCan station Meanook (red dot) is very close to AUTUMNX station Athabasca. 60, 70, and $80^{\circ}$ geomagnetic latitude lines are marked with yellow lines 
Table 1 Sites of the AUTUMN array in western Canada. Geomagnetic coordinates given are for 2014 based on the IGRF routines online at http://wdc.kugi.kyoto-u.ac.jp/igrf/gggm/index.html

\begin{tabular}{|c|c|c|c|c|c|}
\hline Site & Geo Lat & Geo Lon & Mag Lat & Mag Lon & L-value \\
\hline Inuvik, NT & 68.41 & 133.76 & 71.04 & $86.48 \mathrm{~W}$ & 9.47 \\
\hline Whitehorse, YT & 60.77 & 135.09 & 63.77 & $79.95 \mathrm{~W}$ & 5.12 \\
\hline Fort St John, BC & 56.24 & 120.74 & 61.70 & $61.26 \mathrm{~W}$ & 4.45 \\
\hline La Ronge, SK & 55.15 & 105.26 & 62.69 & $42.41 \mathrm{~W}$ & 4.75 \\
\hline Meanook, AB & 54.61 & 113.34 & 61.15 & $51.87 \mathrm{~W}$ & 4.30 \\
\hline Athabasca, AB & 54.60 & 113.64 & 61.11 & $52.22 \mathrm{~W}$ & 4.28 \\
\hline Saskatoon, SK & 52.16 & 106.53 & 59.60 & $42.76 \mathrm{~W}$ & 3.91 \\
\hline Red Deer, AB & 52.14 & 113.83 & 58.68 & $51.34 \mathrm{~W}$ & 3.70 \\
\hline Calgary, AB & 50.88 & 114.33 & 57.37 & $51.42 \mathrm{~W}$ & 3.44 \\
\hline Lethbridge, $A B$ & 49.63 & 112.86 & 56.34 & $49.27 \mathrm{~W}$ & 3.26 \\
\hline
\end{tabular}

A striking aspect of the southern hemisphere is that it has considerably more water than does the northern. Magnetometers require a solid footing, on land or ice, and no practicable magnetometer operates in the ocean. In terms of meridian arrays, the west coast of South America features several subauroral stations of SAMBA (SAMBA/AMBER Project 2013), but these are not in the auroral zone. The Antarctic Peninsula shows several stations, primarily those of the British Antarctic Survey (BAS), somewhat north-south aligned along the coast. There are obvious chains in the continental interior. These are mostly BAS and Virginia Tech instruments, and have magnetic conjugacy with Greenland. Conjugacy in geomagnetism means being on the same geomagnetic field line. As these change depending on conditions in space (and slowly due to secular variation of the internal field), conjugacy can change, but is still meaningful in an averaged sense and since changes are rarely extreme. Conjugate points in space or on the ground (pairs) are best determined by accurate field line tracing. Since we do not know the magnetic field at all points in space at any given time, this tracing is often based on in situ data sampled at many locations at different times, and parametrized according to indices or solar wind parameters. In practice the models related to those of Tsyganenko (1989) have been widely used to represent the magnetic field in space (when added to a suitable internal field model) and allow field line tracing. Conjugacy with one or more spacecraft is possible, and on closed field lines, with two ground locations. Such conjugacy is temporary for most spacecraft, and having more than one conjugate or even near-conjugate spacecraft on a given field line is rare. The exception is for geosynchronous spacecraft, which due to diurnal variations in magnetic fields do not remain exactly conjugate, but continuously remain close to conjugate to two points near their longitude and at roughly $\pm 65^{\circ}$ magnetic latitude. The average daily path of conjugacy for the Geostationary
Operational Environmental Satellite (GOES) East satellite, which is constantly maintained in place for (mainly) weather monitoring, encloses NRCan station Sanikiluaq near the AUTUMNX array, and AUTUMNX station Kuujuarapik, and is shown in Fig. $4 .{ }^{1}$ For spacecraft in other locations than geosynchronous, it is normally necessary to do field line tracing to determine conjugacy as the position of the spacecraft changes (and conjugacy may be lost if, for example, the spacecraft exits the magnetosphere). For ground stations, average conjugacy may be retained for years or more, and the laborious procedure of field-line tracing can be avoided. Using best field models, geomagnetic coordinates can be defined, such as the Corrected Geomagnetic Coordinates or CGM updated by Gustafsson (1984) and presented as a table allowing conversion between geodetic and geomagnetic coordinates. Updated coordinate systems such as PACE (Baker and Wing 1989) and its modification AACGM (Shepherd 2014) usually use a series representation and attempt to overcome issues of poorly defined magnetic coordinates near the equator. The latter is of little concern here due to our focus on the auroral zone.

Comparison of geomagnetic coordinates for ground station pairs gives a good indication of their average conjugacy. Rough ground conjugacy is shown in geomagnetic coordinates in Fig. 3, where northern hemisphere stations are shown by black dots (red for AUTUMNX) and southern hemisphere stations by blue dots. Conjugacy, particularly in the auroral zone, is rare. Virginia Tech and British Antarctic Survey stations form a conjugate chain, nearly overlapping west Greenland stations at about 40 degrees geomagnetic longitude and within the auroral zone. There is some conjugacy possible between the near-coastal locations in Antarctica as typified by Syowa (Motoba et al. 2014) and the island of Iceland, shown here by some conjugated points near 75 degrees CGM longitude near the southern edge of the auroral oval. Unfortunately, the three western American chains are not conjugate to Antarctica 


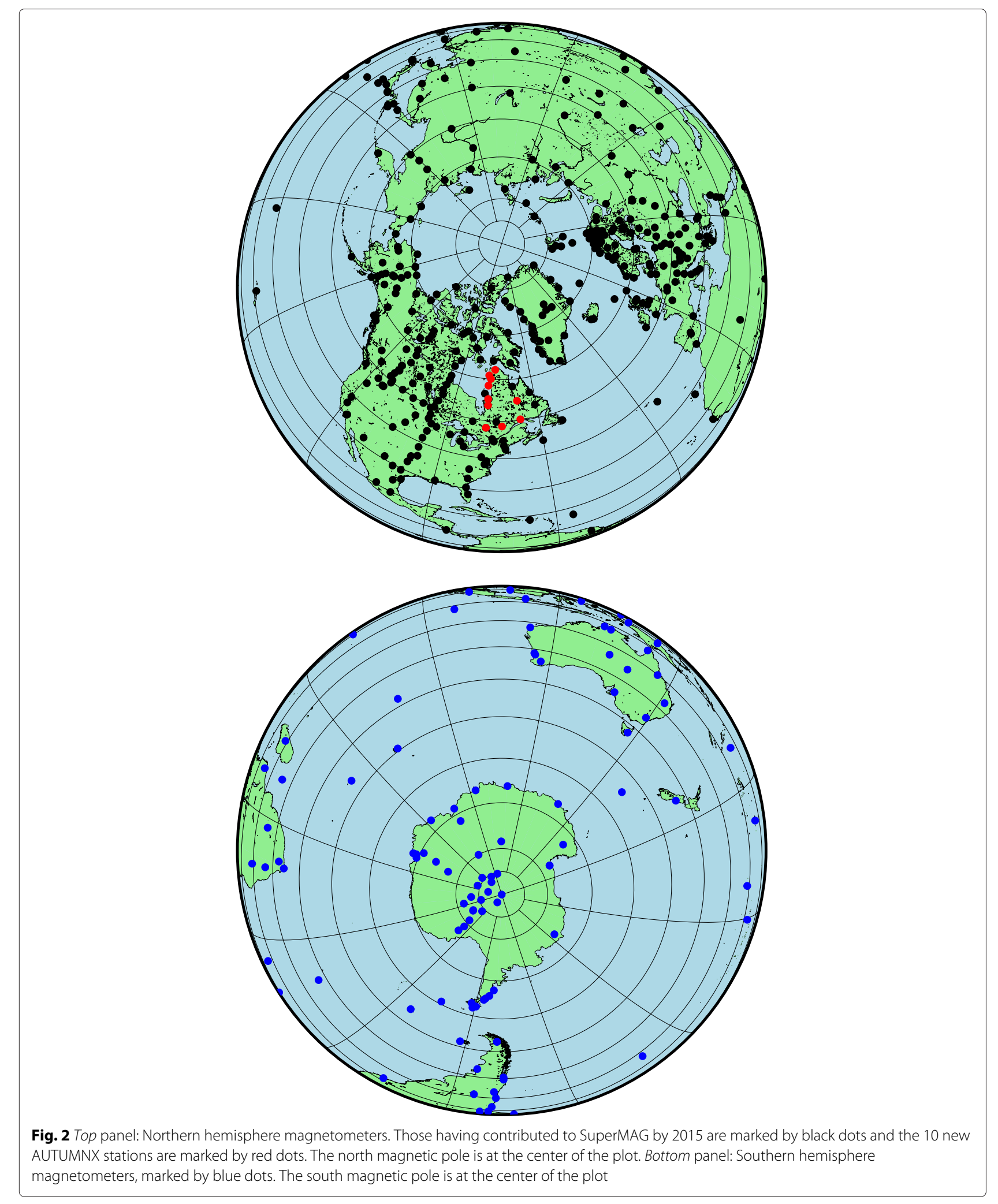

at all. Within North America, AUTUMNX is conjugate to land (ice) in Antartica, but with no magnetometers presently there. Some Antarctic peninsula magnetometers between 10 and 15 degrees are conjugate to the east coast of North America and about 5 degrees away from the most southerly AUTUMNX magnetometers. The conjugacy of 


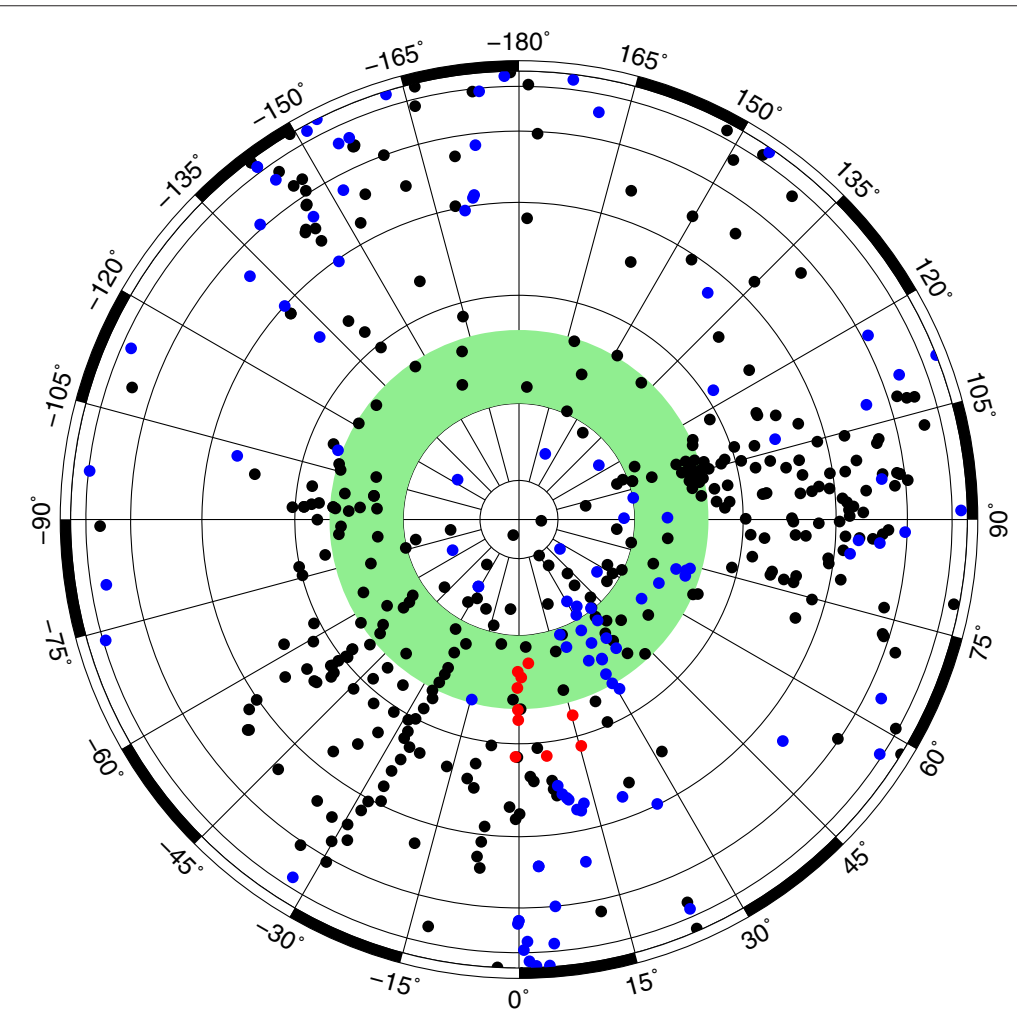

Fig. 3 Geomagnetic coordinate view oriented to facilitate interhemispheric comparison, with orientation approximately matching that of the top panel of Fig. 2. Northern hemisphere magnetometers are indicated with black dots, except that 10 AUTUMNX magnetometers are indicated by red dots. Southern hemisphere magnetometers are plotted with inverted geomagnetic latitude using blue dots. Orthographic projection centered on the magnetic pole is used to give greater emphasis to polar regions. The grid is 15 degrees in both geomagnetic longitude (marked around edge) and in geomagnetic latitude (not marked). The approximate usual auroral zone is marked in green between geomagnetic latitudes 65 and $75^{\circ}$. See text for details

eastern North America to points in the Antarctic has been recognized for at least half a century (Wescott 1966), and sometimes has been exploited (Surkan and Lanzerotti 1974), including in a location very close to the present AUTUMNX magnetometer at Saint-Félicien. We hope to enhance the scientific utility of AUTUMNX through installation of new conjugate instruments. A proposal called PRIMO has been put forward to place magnetometers close to conjugate points of AUTUMNX stations. A site at the West Antarctic Ice Sheet (WAIS) Divide has also been proposed (Lessard et al. 2014) due to facilities already present there, and its near conjugacy to Sanikiluaq and now to AUTUMNX site Inukjuak.

AUTUMNX also helps to address the interrelationship between the day and night sides of Earth. The International Space Weather Meridian Circle Program (Wang 2010) will link instruments being placed along the $120^{\circ}$ geodetic meridian (at subauroral latitudes) with those in the opposite hemisphere. The AUTUMNX secondary chain is close to this complementary meridian, and the main East Hudson Bay chain about one hour of magnetic local time west of it. Plasma transport across the polar cap links the day and night sides (Cowley 2000; Zhang et al. 2015). Details of this, such as the link to substorms
(Nishimura et al. 2010) continue to be investigated. Well instrumented meridians in a day-night configuration can inform space weather prediction and basic science (Wang 2010).

\section{The AUTUMNX array}

AUTUMNX fills an important gap in continental magnetic coverage in North America and offers possibilities for conjugate studies. The increased density of stations enhances studies of the entire substorm current wedge, nominally extending about $70^{\circ}$ in longitude, when it is centered over North America. As Earth turns toward the east, and since substorm activity peaks in the midnight sector, AUTUMNX can also indicate substorm-related space weather events earlier than most other stations on the continent. The location is also important since major hydroelectric projects are found in Québec, with lengthy transmission lines extending over a resistive continental shield geology (Wei et al. 2013). This combination leads to a sensitivity to geomagnetic induced currents (GIC) in susceptible major infrastructure.

AUTUMNX is structured as two meridional chains spanning the northern auroral zone, stretching along the eastern shore of Hudson Bay (EHB: near 78 degrees 


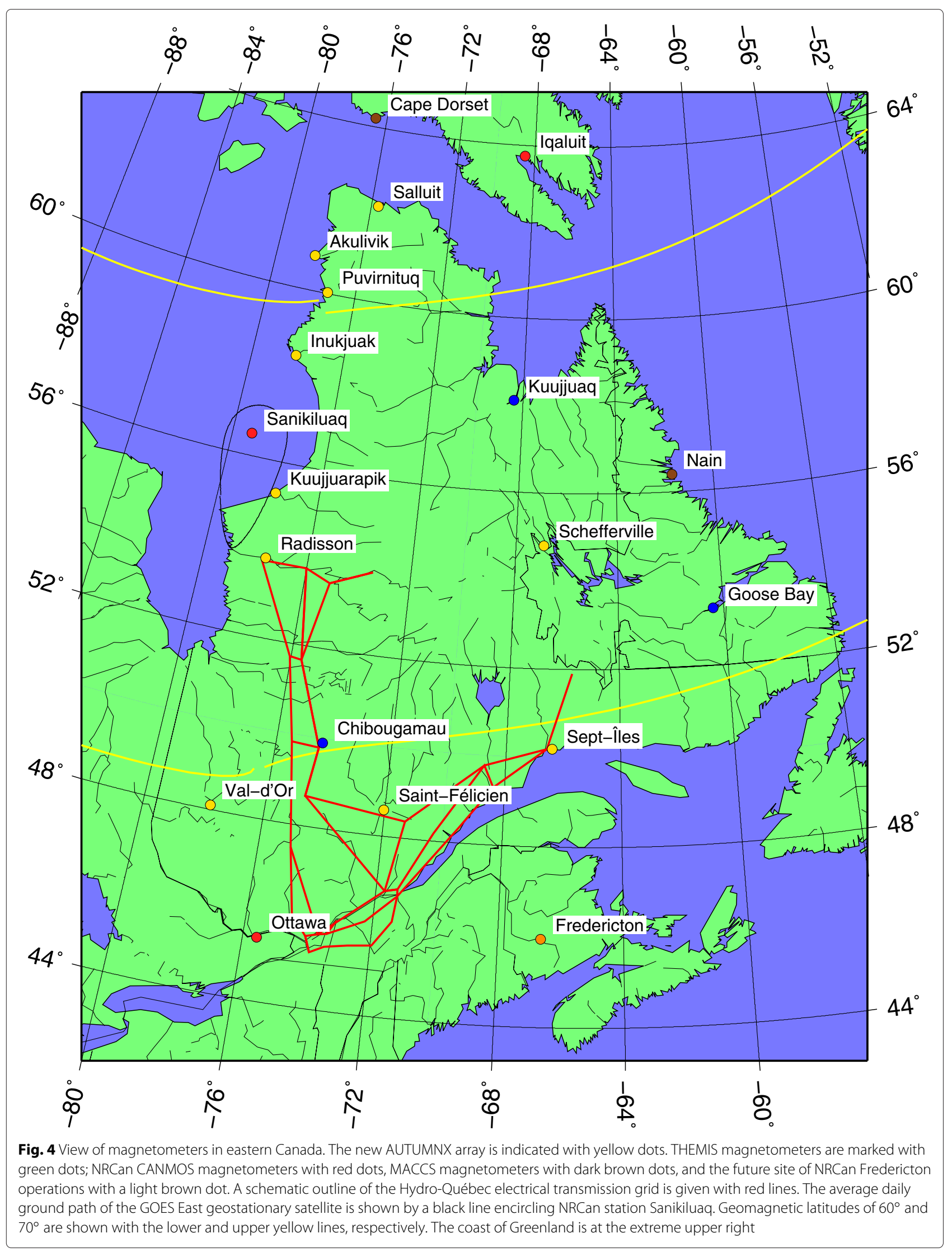


west geodetic longitude), and roughly along the QuébecLabrador border (68 degrees west), with one intermediate station. When select magnetometer stations from outside networks complement AUTUMNX s coverage (Fig. 4), these two chains span the entire auroral zone, from $55.38 \mathrm{~N}$ to $73.71 \mathrm{~N}$ geomagnetic latitude (Table 2). The enhanced coverage in eastern North America now offers good opportunities for Antarctic conjugacy, and several stations near enough to the GOES East footpoint for satellite conjugate studies to be productive. For example, magnetic inversion on a meridian chain can establish electrojet positions and strengths (Connors and Rostoker 2015) and allow their relation to geosynchronous field variations to be investigated (see case study below). In order to determine phase shifts associated with fieldaligned resonances which may be associated with pulsations detected at geosynchronous orbit, a meridian chain near the footpoint is needed (Ziesolleck et al. 1996). Studies such as longitudinal location of the substorm current wedge (Connors et al. 2014) or determination of the phase speed and mode of ULF waves (Mann et al. 2002) require a longitudinal distribution of stations. This is provided in AUTUMNX by having three stations east of the main EHB chain, and by being able to compare to data to that from other networks. In Table 2, the names of neighboring magnetometer networks in Eastern Canada are given, and these are color coded on the map of Fig. 4. Coordinates in the table are given in geodetic and geomagnetic coordinates, including calculated L-values. Geomagnetic coordinate conversion was done using the site of the World Data Center for Geomagnetism, Kyoto (http://wdc.kugi. kyoto-u.ac.jp/igrf/gggm) and L-value calculations using the VITMO IGRF/DGRF model (http://omniweb.gsfc. nasa.gov/vitmo/irgf_vitmo.html). In Fig. 4, AUTUMNX stations are indicated by yellow dots. The other arrays flanking AUTUMNX are: MACCS (brown), operated by Augsburg College; CANMOS (red), operated by NRCan, and THEMIS (blue), operated by the University of Calgary. Sanikiluaq, Ottawa, and Iqaluit are observatory-class facilities of the national network. The city of Fredericton is indicated in light brown and does not currently have a magnetometer. However, it is likely that NRCan will soon operate facilities there, making a southerly extension of the AUTUMNX eastern chain. From the nearby coast southward, the Atlantic Ocean precludes installation of further magnetometers until one reaches the Caribbean Sea, where the USGS site of San Juan is approximately in this meridian.

Approximate CGM latitude lines of 60 and $70^{\circ}$ are plotted in yellow crossing Fig. 4, respectively at lower $\left(48-52^{\circ}\right)$ and higher $\left(59-64^{\circ}\right)$ geodetic latitudes. The $70^{\circ}$ CGM latitude line touches the west coast of Greenland with its chain of magnetometers. The lowest geomagnetic latitude among Greenland magnetometers is for Narsarsuaq

Table 2 Sites of the AUTUMNX array in Québec, with complementary sites from other arrays in eastern Canada. The top block is the Eastern Hudson Bay chain, the middle the Québec-Labrador chain, and the bottom nearby distributed sites. Fredericton is anticipated but not yet installed. See Table 1 for description of geomagnetic coordinates

\begin{tabular}{|c|c|c|c|c|c|}
\hline Site & Geo Lat & Geo Lon & Mag Lat & Mag Lon & L-Value \\
\hline Cape Dorset (MACCS) & 64.21 & 76.53 & 73.71 & -6.10 & 12.71 \\
\hline Salluit & 62.20 & 75.63 & 71.71 & 4.49 & 10.16 \\
\hline Akulivik & 60.80 & 78.20 & 70.26 & 8.11 & 8.77 \\
\hline Puvirnituq & 60.03 & 77.28 & 69.51 & 6.68 & 8.16 \\
\hline Inukjuak & 58.46 & 78.07 & 67.92 & 7.62 & 7.08 \\
\hline Sanikiluaq (CANMOS) & 56.53 & 79.21 & 65.96 & 8.97 & 6.03 \\
\hline Kuujjuarapik & 55.27 & 77.74 & 64.73 & 6.86 & 5.49 \\
\hline Radisson & 53.79 & 77.61 & 63.25 & 6.58 & 4.94 \\
\hline Chibougamau (THEMIS) & 49.41 & 74.36 & 58.90 & 2.19 & 3.75 \\
\hline Val-d Or & 48.19 & 77.78 & 57.64 & 6.45 & 3.49 \\
\hline Ottawa (CANMOS) & 45.41 & 75.68 & 54.89 & -3.74 & 3.02 \\
\hline Iqaluit (CANMOS) & 63.73 & 68.51 & 73.23 & 6.35 & 12.01 \\
\hline Kuujjuaq (THEMIS) & 58.10 & 68.38 & 67.58 & 5.92 & 6.88 \\
\hline Schefferville & 54.80 & 66.90 & 64.24 & 7.64 & 5.30 \\
\hline Sept-Îles & 50.21 & 66.38 & 59.64 & 7.95 & 3.92 \\
\hline Fredericton (UNB) & 45.95 & 66.66 & 55.38 & 7.33 & 3.10 \\
\hline Nain (MACCS) & 56.53 & 61.68 & 65.80 & 14.87 & 5.95 \\
\hline Goose Bay (THEMIS) & 53.30 & 60.41 & 62.52 & 15.97 & 4.69 \\
\hline Saint-Félicien & 48.68 & 72.51 & 58.18 & 0.14 & 3.60 \\
\hline
\end{tabular}


at approximately $65^{\circ}$, close to those of AUTUMNX site Schefferville and MACCS site Nain. The sites in eastern North America (including NRCan CANMOS observatory St. John's, which is on the island of Newfoundland and just off the map near $48^{\circ}$ geodetic latitude) now provide relatively good coverage for active conditions, which may see activity centered at latitudes below those covered by the Greenland chain. The slight discontinuities in the geomagnetic latitude lines occur at $0^{\circ}$ corrected geomagnetic longitude and arise from the interpolation method used to produce the lines. These discontinuities show that $0^{\circ}$ CGM longitude is very close to the East Hudson Bay part of AUTUMNX.

Figure 4 also shows schematically, as red lines, the Hydro-Québec electrical transmission network. This network suffered a major space weather related blackout on March 13, 1989, as described by Bolduc (2002). The low subsurface conductivity in this region leads to a larger development of electric fields in response to changing geomagnetic fields $(\mathrm{dB} / \mathrm{dt})$ according to Faraday's Law, than in most other regions of North America (Wei et al. 2013), leading to larger GIC. Modern risk assessment methodologies and regulations applied to large interconnected technological systems such as power grids emphasize understanding response to external conditions, and the measurement of the inputs (NERC 2013 ). AUTUMNX is well placed to make $\mathrm{dB} / \mathrm{dt}$ measurements relevant to the operation of the Hydro-Québec power network.

\section{Instrumentation}

Both AUTUMN and AUTUMNX feature online magnetometers, most (and all in AUTUMNX) supplying data at $2 \mathrm{~Hz}$. Data is available in near-real-time, with delays largely dependent on the local network to which instruments are attached. Over years of operating AUTUMN, we addressed issues of power, reliability, and connectivity, and integrated lessons learned into the design and installation of AUTUMNX. We now describe the current and standardized aspects of AUTUMNX instrumentation.

\section{Magnetometer}

AUTUMNX network hardware is based upon that of AUTUMN, operated in Western Canada since 2003 by Athabasca University. Original AUTUMN deployments used PC hardware running under Linux. Most hardware failures were associated with the $\mathrm{PC}$, and the power draw was relatively large. Over the years, AUTUMN has tested various types of computer platforms. A major step forward was the adoption of modern single board Linux computers known as Beaglebones/Beagleboards. On the other hand, the magnetometer design has remained quite stable. Like AUTUMN, the AUTUMNX network is based upon the THEMIS GMAG ground-based fluxgate magnetometer (Russell et al. 2008). It consists of a sensor head, electronics box, and GPS antenna, and was designed to complement space-borne magnetic measurements of the THEMIS mission, launched in 2007, with ground-based vector measurements of the geomagnetic field at $2 \mathrm{~Hz}$ cadence. It noted for its high resolution (10 pT), low noise ( $\pm 25 \mathrm{pT} \mathrm{rms})$, high temperature stability $(0.1 \mathrm{nT} / \operatorname{deg} \mathrm{C})$, and large dynamic range $( \pm 70000 \mathrm{nT})$. To assure temperature stability, the sensor head is preferably buried in soil, which posed some constraints in the rocky landscapes of northern Québec. Some of the sites of the temporary network Polaris (Connors and Rostoker 2015) were in the same towns as AUTUMNX, but on rock, which meant that the same sites could not be reused.

\section{Electronics support}

The THEMIS GMAG is supported by a switchable, uninterruptable, filtered power supply, instrument control and data logging computer, and Internet connectivity, housed in a ruggedized container. This support unit, called the AUTUMNX ground based observatory (or GBO) is largely based on the THEMIS GBO (Harris et al. 2008), following its design goals and functionality. The overall structure, shown in Fig. 5, consists of an 8-U (35.6 $\mathrm{cm}$ high) 19-inch rack in a moulded plastic shock enclosure that houses a rack-mountable uninterrupted power supply, networked AC power distribution unit, control computer, network router/modem, and the THEMIS

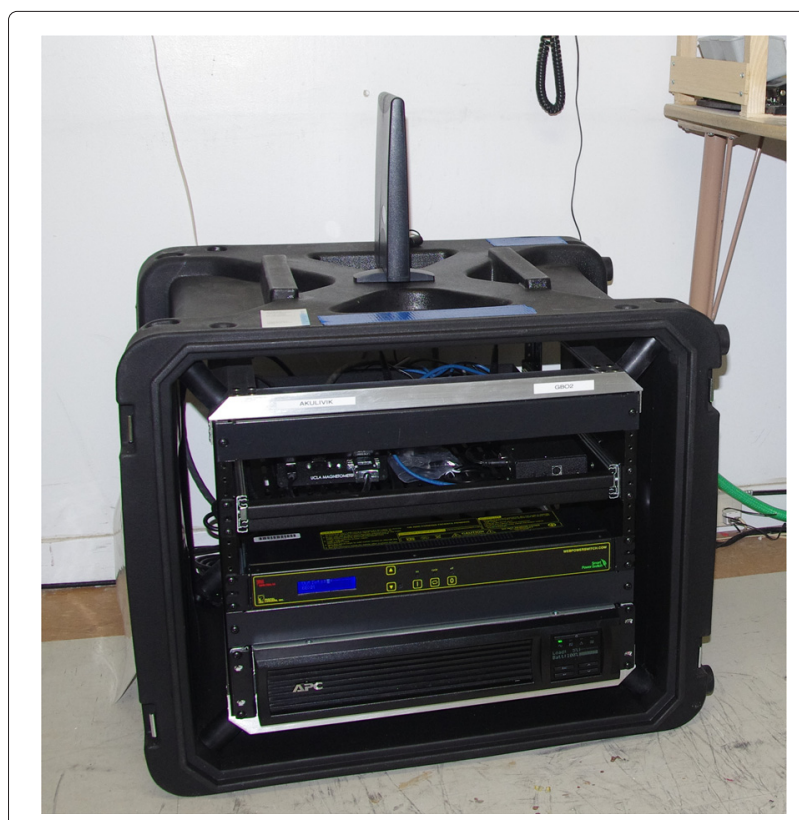

Fig. 5 AUTUMNX ground-based observatory unit. At bottom is a large UPS unit, in the middle a network control center, and on the tray a Beagleboard computer and THEMIS magnetometer control box. An antenna used at some sites sits on top of the unit 
GMAG electronics box. The rack-mount shock enclosure is weatherproof and serves as a shipping container and instrument rack when deployed. While the magnetometer sensor head must be buried outside, the GBO must be housed in a building with available AC power. The THEMIS GMAG's GPS antenna and GBO's communication antenna (if wireless Internet is used) are mounted on the building's roof. The magnetometer head is situated as far as possible from the building where the GBO is housed, thus the GMAG uses a 100-foot (30 m) or 150-foot ( $45 \mathrm{~m}$ ) signal cable. In two cases (Akulivik and Puvirnituq), the instruments were by necessity installed in large pails of sand in disused buildings with sturdy floors. The Akulivik site seems noisy, especially in the $B_{X}$ component, which is thought to be due to a geologically anomalous site. This issue is being investigated with data from the Polaris network (Connors and Rostoker 2015).

\section{Communications and data}

The advent of reliable yet affordable data connectivity in northern Québec significantly aided the feasibility of deploying AUTUMNX instrumentation, giving the capability to reliably send data back in near-real time. Northern EHB sites from Salluit south to Inukjuak use wireless broadband Internet (through the local Internet service provider Tamaani) that is uplinked through satellite. AUTUMNX sites in Southern Quebec use LTE mobile wireless Internet, excluding Val-d Or, which uses wired ADSL. The remaining sites in Schefferville and Kuujjuarapik use Ka-band satellite Internet. All connectivity methods provide an unblocked public IP address permitting incoming logins and outgoing telemetry transmission. Dynamic DNS services provide fixed, humanreadable DNS addresses for each of the AUTUMNX sites.

Each AUTUMNX GBO gathers nearly $2.7 \mathrm{MB}$ of raw data per day, or approximately $84 \mathrm{MB} /$ month. The data gathering software logs the raw magnetic data in THEMIS GMAG binary format to the local disk while also transmitting it and housekeeping data via the lightweight UDP protocol. Taking into account network overhead and the data collection program's UDP-based real-time telemetry transmission, a $500 \mathrm{MB} /$ month data plan is more than adequate to service a typical AUTUMNX GBO site. The AUTUMNX data repository at Athabasca University (http://autumn.athabascau.ca) downloads accumulated data from each AUTUMNX station every hour or less using the rsync file transfer program, which has redundancy and ability to ensure that requested data is eventually obtained. Each AUTUMNX station continuously uploads current data and housekeeping telemetry every 10 seconds back to the AUTUMNX repository in the form of UDP datagrams, thus providing real time data reporting capabilities. The northern network infrastructure and the UDP protocol as a whole are not reliable, meaning that data packets may not arrive due to the network temporarily going down or other conditions. In the event that the network goes down, ground magnetic data continues to $\log$ to local disk provided there is electricity to power the control computer and magnetometer. The uninterruptable power supply (UPS) can maintain electric supply for several hours, ensuring continuity of data gathering function. Real time data and telemetry are lost during an outage, but rsync transfers resume once Internet is restored. Rsync resumes downloading the data that accumulated during the power or network outage, thus no data will be lost. Data loss was a problem with older magnetometer data collection systems like CANOPUS, which did not use local data storage (Mann et al. 2008).

\section{Computer hardware and software}

A low power (2W) single-board computer (SBC) based on the ARM Cortex A8 processor, called the BeagleBoard XM (BBXM), serves as the AUTUMNX GBO's instrument control and data gathering computer. The BBXM runs an ARM version of the popular Ubuntu Linux ver. 14.04 (server edition), providing a low overhead (nongraphical) Linux environment with performance levels similar to personal computers from the early 2000s. The operating system and local archival storage space are on a fingernail-sized $8 \mathrm{~GB}$ industrial-grade microSD card. USB secondary data storage is used for redundancy.

Developers of the THEMIS GMAG wrote a nongraphics-based magnetometer control program called GBOMag that controls the THEMIS GMAG, gathering and logging data, and transmitting real time data and system status telemetry. This software duplicates the data logging functionality of the original LabView-based control software designed for the Geomagnetic Event Observation Network by Students (GEONS) program (Peticolas et al. 2008), which placed THEMIS GMAG magnetometers in American schools to provide ground based geomagnetic monitoring for NASA's THEMIS mission. GBOMag is substantially less impactful on resources than the LabView THEMIS client and functions as a commandline-based Linux service. Additional software was developed at Athabasca University to add a web-based, mobilefriendly user interface (UI) based on modern web technologies (e.g. AJAX background data transmission, Bootstrap open source framework for web interface development). The web UI works in conjunction with GBOMag and the Linux host's web server, allowing easy instrument configuration and management. Each AUTUMNX station can be managed directly through its web UI.

\section{Data distribution}

As mandated by the Canadian Space Agency's Geospace Observatory (GO) Canada geospace monitoring program, all data gathered is provided free to the public in near- 
real time. The AUTUMNX dataset, updated at least hourly from the magnetometer array, is made available through the AUTUMN-AUTUMNX data portal hosted at Athabasca University (http://autumn.athabascau.ca). The site provides a simple interface to browse and download the magnetic data in raw binary form, or in IAGA2002 format that is text based and thus human readable. Data is offered in $2-\mathrm{Hz}$ or reduced 1-minute cadence. Data is stored at Athabasca University's data center at the main campus in Athabasca, Alberta. The AUTUMNX data is sent on to Natural Resources Canada (NRCan), CDAWeb (NASA Goddard), THEMIS data repository (UC Berkeley), and SuperMAG (Johns Hopkins University). Some of these secondary sources redistribute it in various formats.

The web user interface for AUTUMNX (one level on from the entry page mentioned above, which separately allows access to AUTUMN or AUTUMNX) is shown in Fig. 6. This shows site status at a glance for the whole array for a selected day (in this case the Kuujuarapik site had no connectivity), as well as a quick overview of data. In this case, features of activity on February 17, 2015 are immediately visible, and here are highlighted with boxes. The active period from 6 to 13 UT (outlined for the $B_{X}$ component at stations INUK and PUVR) had consistently negative $B_{X}$ component values at all auroral zone stations, a negative excursion of the $B_{Y}$ component near its beginning, and $B_{Z}$ component perturbations which were positive in the northern auroral zone but negative at the more southerly station Radisson. That station also showed a large impulsive feature near the end of the UT day, most notable in the $B_{Z}$ component. Since impulsive features were also seen at much the same time at other stations, this appears to be a real signal. Based on such inspection on the web interface, these two periods of this day were selected for detailed study, with results given below. To the right of the data plots for each station (not all of which are shown in this screenshot) are links (in blue, or purple if already used) allowing selection of data for more detailed display or download. Our downloads are in IAGA2000 format, but our hourly feeds to CDAWeb and THEMIS sites allow them to be accessed in other popular formats also.

\section{Results and discussion}

Operation of AUTUMNX has produced a large amount of data since late 2014. Here we discuss two distinct types of event that took place on February 17, 2015. These events were identified by examining in sequence web summary plots similar to those of Fig. 6, where they are shown in outlined boxes.

\section{Initial results from AUTUMNX}

Initial interpretation of February 17, 2015 data during the active period 6-13 UT can be done using the right hand rule. This suggests that for a westward electrojet, the magnetic field at the surface will have a southward perturbation (negative $B_{X}$ : data shown in Fig. 6 are relative to the average value for the day). Indeed, all stations from Radisson northward show irregular negative $B_{X}$ (i.e. southward) pertubations during this time, and a westward electrojet must have been over or near them. The field north of a westward electrojet is downward (positive $B_{Z}$ ), and south of it upward (negative $B_{Z}$ ). Radisson is the only one of the more northerly stations to show negative $B_{Z}$ perturbations during the active period, the rest showing positive ones. It may be inferred that the center of the westward electrojet was north of Radisson but south of the other northerly stations. In both the $B_{X}$ and $B_{Z}$ components there are irregular increases in amplitude reminiscent of substorm onsets. These are most visible at Akulivik, which seems in general to have noise in the $B_{X}$ component, but shows the $B_{X}$ decreases most clearly. The entire array shows a negative $B_{Y}$ perturbation near $6 \mathrm{UT}$, near the beginning of the active period. The right hand rule is not helpful in a simple way in explaining this perturbation. More detailed investigation showed that this active period appeared to be a Steady Magnetic Convection event modulated by solar wind driving, and it is the topic of a subsection below.

In the last hours of the UT day of February 17, 2015, the $B_{X}$ perturbation at Radisson became generally more positive, accompanied by negative $B_{Z}$ perturbations at this station and at Inukjuak nearly five degrees to its north. These signatures are consistent with an eastward electrojet whose center was south of Radisson. The late UT hours at this array near $78^{\circ}$ west geodetic longitude correspond to evening in magnetic local time and eastward electrojets are common in that sector. A complex but very discrete feature appeared at roughly 23:30 UT, with positive and negative $B_{X}$ perturbations of several hundred nT at Akulivik in the north and Inukjuak five degrees south of it. Negative $B_{Y}$ perturbations observed at all stations had maximal amplitude (ca. -400 nT perturbation) at Radisson, and $B_{Z}$ decreased by about $700 \mathrm{nT}$ there. Since this spike clearly features a large $\mathrm{dB} / \mathrm{dt}$, it is of interest to the AUTUMNX aim of assessing the regional effects of geomagnetically induced currents. Inspection of GOES 13 geosynchronous conjugate data showed detection in space of a discrete event at the same time, and THEMIS solar wind and magnetospheric data gave more information. The event is discussed in more detail as an "impulsive event" in a subsection below.

\section{Magnetogram inversion}

Before proceeding to discuss the events, we describe a tool known as Automated Meridian Modeling (Connors and Rostoker 2015) which is useful in interpreting magnetic meridian chain data. Readers are referred to the 
$\leftarrow \rightarrow \mathbf{C} \square$ autumn.athabascau.ca/autumnxquery.php?year $=2015 \&$ mon $=02 \&$ day $=17$

AUTUMNX Magnetometer Network

Year: 2015 - Month: February - Day: 17 Get Data

«< Prev Day Next Day $>$

Date: 2015/02/17

SALU

Salluit, $Q C$

lat: 62.20 lon: -75.65
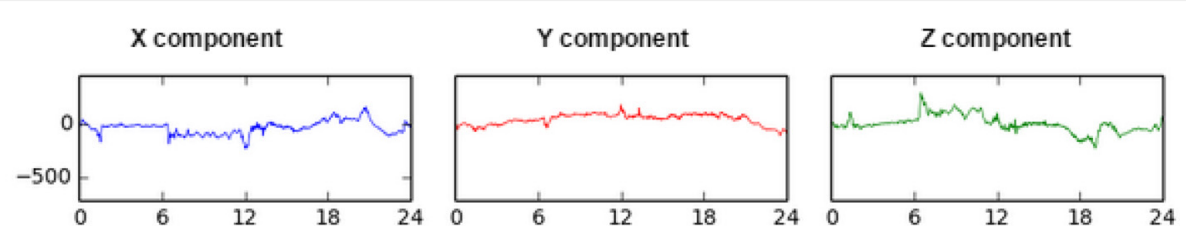

1-min plot

1-min data

$2 \mathrm{~Hz}$ data

Multi-day

AKUL

Akulivik, QC

lat: 60.82 lon: -78.15
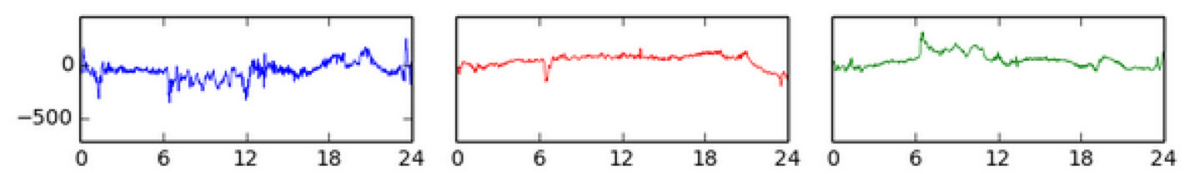

1-min plot

1-min data

$2 \mathrm{~Hz}$ data

Multi-day

\section{PUVR}

Puvirnituq, QC

lat: 60.05 Ion: -77.29
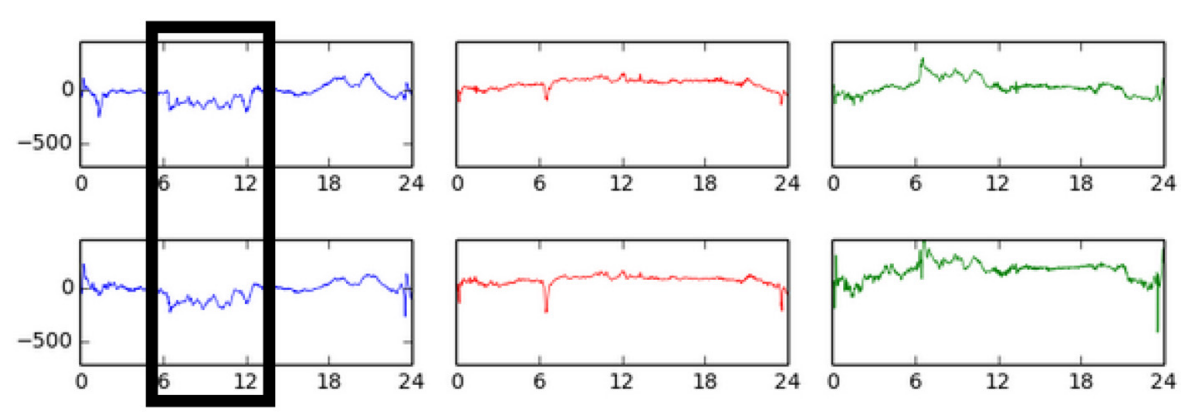

1-min plot

1-min data

$2 \mathrm{~Hz}$ data

Multi-day

\section{INUK}

Inukjuak, QC

lat: 58.47 lon: -78.08

\section{KJPK}

Kuujjuarapik, QC

lat: 55.28 lon: -77.76

\section{RADI}

Radisson, QC

lat: 53.79 lon: -77.62
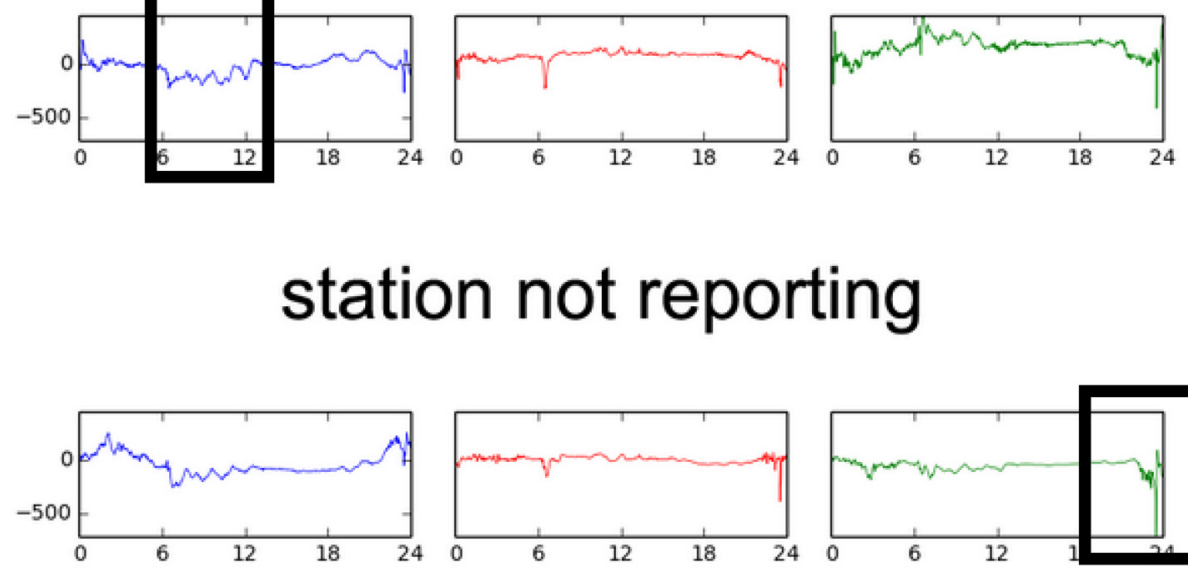

1-min plot

1-min data

$2 \mathrm{~Hz}$ data

Multi-day

\section{station not reporting}

\section{VLDR}

Val-d'Or, QC

lat: 48.05 lon: -77.78
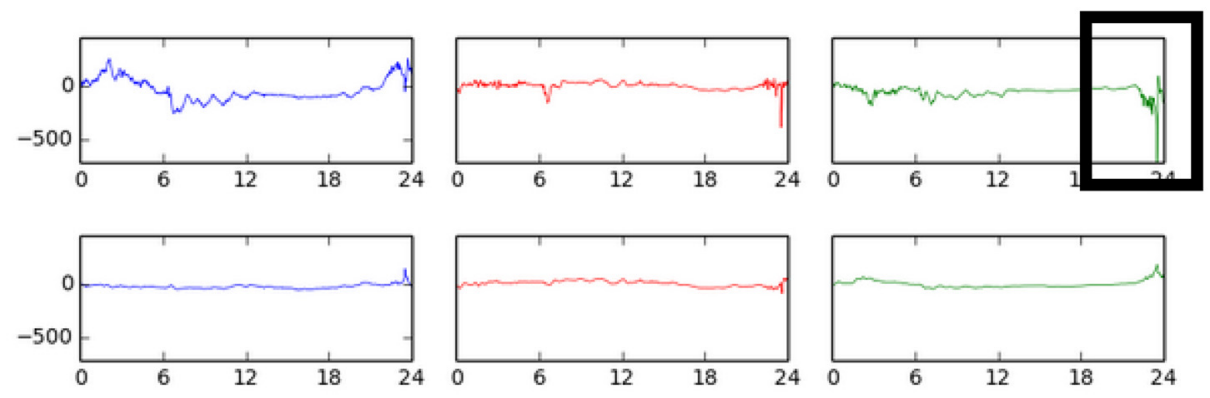

1-min plot

1 -min data

$2 \mathrm{~Hz}$ data

Multi-day

\section{STFL}

Saint-Felicien, $Q C$

lat: 48.65 lon: -72.45
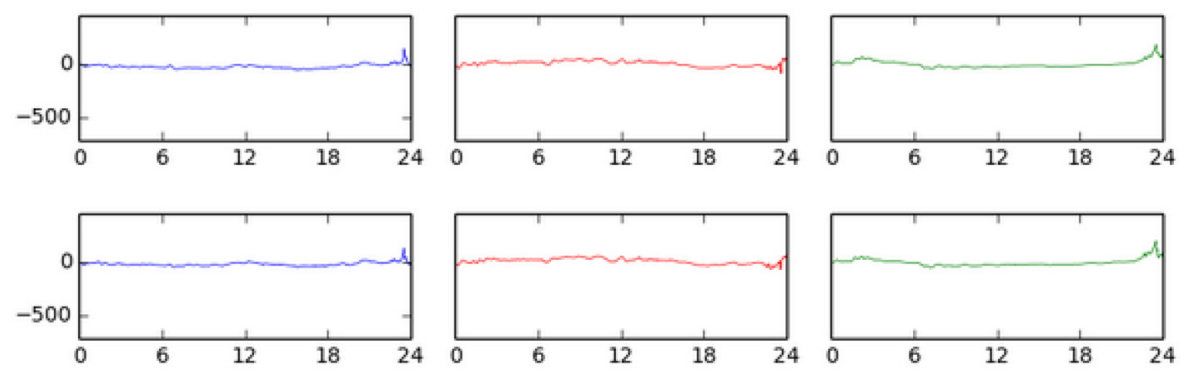

1-min plot

1-min data

$2 \mathrm{~Hz}$ data

Multi-day
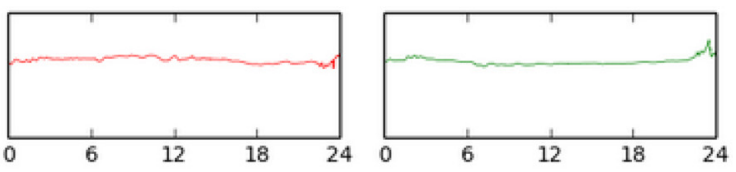

1-min plot

1-min data

$2 \mathrm{~Hz}$ data

Multi-day

Fig. 6 The web page used for viewing the status of AUTUMNX stations and near-real-time and archival data. The $B_{X}$ component points toward magnetic north, $B_{Y}$ toward magnetic east, and $B_{Z}$ vertically downward. Inspection of full-day web pages can draw the investigator $\otimes$ attention to interesting features, two of which are highlighted by boxes, discussed in the text, and with detailed data shown in other figures

companion paper for a detailed description. The intent here is to describe this technique very briefly so that this paper may be understood independently.
The magnetic field due to a current system without rapid time variation may be calculated using the BiotSavart integral, which corresponds to the Ampère Law 
Maxwell equation when integrated over a closed circuit (Jackson 1975). Kisabeth (1979) developed methods of performing this integral for current systems relevant to the substorm problem, including Earth induction. These methods were applied to substorm data by Kisabeth and Rostoker (1977) with particular success in modeling the perturbations arising in meridian chains as measured by magnetometers. The parameters within the models were adjusted manually until a good match was obtained to the data, and parameters in the meridian case chain included the latitudinal borders of the electrojet and its current, along with the depth to a hypothetical superconductor representing Earth conductivity, and the height of the ionosphere. A good match can be found in most cases by allowing the borders and current to vary while using 250 $\mathrm{km}$ and $110 \mathrm{~km}$, respectively, as the depth to the superconductor and the height of the ionosphere. In the papers cited, variation of parameters was done through human estimation. The technique is "forward modeling" in the sense that a model is proposed and parameters varied to match data. Automated Forward Modeling (AFM) is simply the use of the techniques of Kisabeth (1979) (slightly improved to more densely place integration points near an observing point) with a computer routine to optimize the parameters. Since the fitting in geometric parameters is nonlinear, Levenberg-Marquardt optimization (Lampton 1997) is used, implemented in the $C$ language with the routines of Press et al. (1992). As described here, the technique is used for meridian chains, i.e. to study variations in latitude due to current systems (electrojets) assumed to be long and flow in the east-west (magnetic coordinates) direction. However, Kisabeth and Rostoker (1977) and Kisabeth (1979) showed more general use for two-dimensional distributions of observing sites and with complex three-dimensional current distributions. Connors et al. (2014) showed that a substorm current wedge three-dimensional model gave currents that were in good agreement with the field-aligned currents independently derived from AMPERE data in space during a substorm.

\section{Steady magnetospheric convection on February 17, 2015} Most of the magnetograms from AUTUMNX for February 17, 2015 are visible in Fig.6. The period 6-12 UT is dominated by a westward electrojet as deduced from inspection. We applied AFM to determine to what extent a simple electrojet could represent the data. A finite and directly westward electrojet has no $B_{Y}$ (eastward) component at its center, so the modeling is based on $B_{X}$ (northward) and $B_{Z}$ (downward) perturbation data only, a variant which when used on a meridian we refer to as Automated Meridian Modeling or AMM (Connors and Rostoker 2015). Field-aligned currents are included in the model but placed far away and with the model meridian central between them, making the physical current determined by the forward model effectively an equivalent current as would be determined by some other inversion techniques. The data was baselined by subtraction of values from March 9, 2015, which was so quiet after 4 UT that its data values could be subtracted directly without smoothing. The model run began at 5 UT. In AFM, an initial guess must be supplied. Here, very rough starting values of electrojet borders at 65 and 75 magnetic latitude, and current of 0.1 MA, were used. AFM always uses a "substorm current wedge" (SCW) current configuration (Connors et al. 2014), but in electrojet modeling the field-aligned current sheets are placed far away and symmetrically about the modeling meridian. In this case they were placed $30^{\circ}$ on either side of the $0^{\circ}$ magnetic meridian where the EHB stations are. The initial scale factor used was 1 , corresponding to a poorly known initial condition. The results of modeling are shown in Fig. 7. After an initial period ending at 6:20 UT when the currents were too weak to permit good determinations of parameters, the electrojet borders were well determined, and from 6:40 to 11:00 UT remained near values of 60 and $72^{\circ}$. During this period, the current across the EHB meridian varied from about 0.1 to $0.5 \mathrm{MA}$. The southern border of the electrojet tended to move northward when the current weakened. The general trend of IMF $B_{Z}$ southward seemed to be reflected in the current, suggesting direct driving. Also, a very steady negative IMF $B_{Y}$ (duskward) dominated the IMF during the entire driven period. Although the variations in ground $B_{X}$ component are reminiscent of multiple substorm onsets, AFM reveals that in fact the electrojet borders were very steady, which is not a characteristic of substorms. We conclude that this activity is more similar to Steady Magnetospheric Convection (Kissinger et al. 2012), despite the variations in current.

Having done an inversion with a simple model, it is important to verify that the model does in fact account for the behavior represented by the data. Plotting input data and model output results based on the parameters found allows this, and Fig. 8 shows this comparison. The $B_{X}$ and $B_{Z}$ components are depicted in black and blue, respectively, with solid lines for observations, and dots as model output for each station in the auroral zone used in the model. Val d'Or, well to the south, was also included in the model, but with equal weight its small perturbations affected the overall model little, and also did not result in a good agreement there, and thus it is not shown. In general the agreement between the model and the data is very good. The agreement is best for the $B_{X}$ component, and we show statistical measures of this in Table 3, with stations listed from north to south. A more general statistical discussion of a similar fit, which also gives formulas for the statistical measures, is presented by Connors and Rostoker (2015), for both the $B_{X}$ and $B_{Z}$ components. Table 3 presents the $\mathrm{a}$ and $\mathrm{b}$ coefficients of a linear fit (regression 


\section{AUTUMNX Feb 172015}
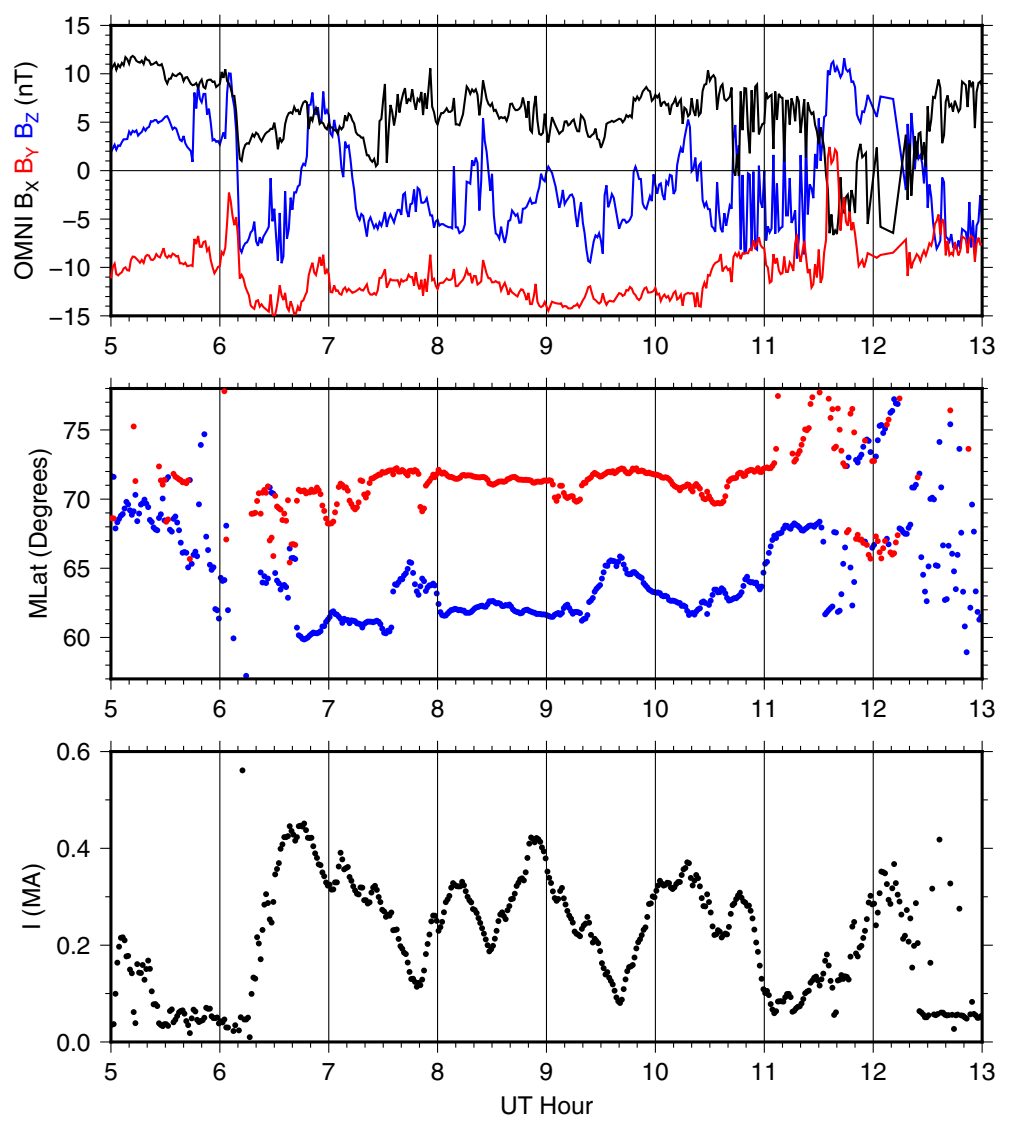

Fig. 7 Inversion results for a simple electrojet model from 5 to 13 UT on February 17 2015. The bottom panel indicates the electric current across the AUTUMNX East Hudson Bay meridian chain, the middle the lower (blue) and upper (red) electrojet borders. The upper panel shows the three components of OMNI propagated interplanetary magnetic field. For a brief period near $12 \mathrm{UT}$, the upper and lower borders may reverse, which has no physical meaning

line) of the model output to the data, where a is the intercept and $b$ the slope of the fit. The standard Pearson $r$ coefficient indicates to what degree there is correlation between the model output and the data input. Finally, $\sigma$ is the standard deviation reflecting offsets about the regression line. In all cases, the a values are small compared to $\sigma$, so that there is no significant offset of the model output from the input. The slopes should ideally be 1 : the two northernmost stations fall short of this, indicating that the uniform model did not place enough current near them, while the central two stations have values close to 1 indicating a good representation there. The southernmost is fairly good also. The $r$ coefficients are high in all cases, and particularly for the central two stations, indicating that the model output is convincingly linearly related to the data input. These results are consistent with the visual impression of a good fit in Fig. 8. We do not present the results for the $B_{Z}$ component, but they clearly would not be as good. In an electrojet, $B_{X}$ has its amplitude maximum near the center, and it is a slowly varying function of latitude. $B_{Z}$, on the contrary, has its sharpest gradients near the center of the electrojet (where its value is zero), and is almost everywhere a more rapidly varying function of latitude than is $B_{X}$. $B_{Z}$ could similarly be sensitive to structure in the electrojet, and as the modeled electrojet has been found to be on average rather wide (about $12^{\circ}$ ), there is a strong likelihood of structure such as a double auroral oval. Throughout the event, $B_{Z}$ of the model generally follows the actual $B_{Z}$ if perhaps with less amplitude. There is every reason to have confidence in the results of the inversion bearing in mind the simplicity of the model. The event was chosen for interest and not necessarily to provide a demonstration of the best possible fit. There is only one station (Radisson) clearly south of the electrojet yet with strong signal: more would be desirable. Nevertheless, the conclusion can be drawn that SMC can feature steady borders with a varying current, a result that would not be able to be deduced, for example, simply through use of the AL or AE index. 


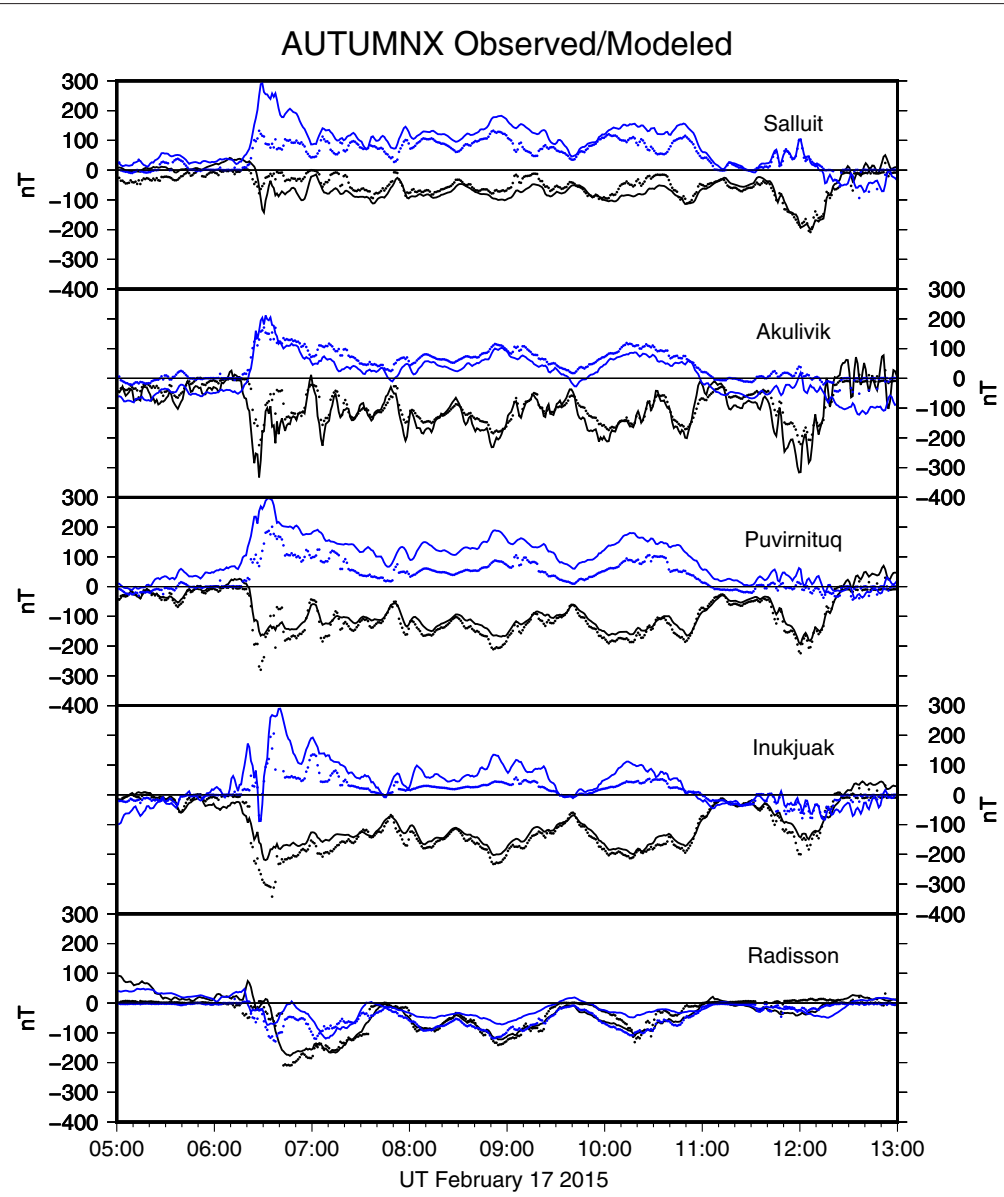

Fig. 8 Comparison of data and model results for the simple electrojet model of Fig. 7. The $B_{X}$ component at each station is marked in black, the $B_{Z}$ component in blue. Baselined observed values are marked with a solid line and model output with dots

We also note that the model fit is not as good near the start of the event (6:00 to 7:00 UT, approximately) as it is later. The $B_{Y}$ component is not shown in Fig. 8 but was shown for most stations at reduced scale in Fig. 6. There was a large $B_{Y}$ perturbation at this time, and $B_{Z}$ has its poorest fits. We can hypothesize that a substorm took place at the beginning of the $\mathrm{SMC}$, as the statistical study of Kissinger et al. (2012) suggested is nearly always the case. An essential aspect of substorms is formation of the substorm current wedge as evidenced by electric currents

Table 3 Statistical results for AMM fitting of $B_{X}$ component of the AUTUMNX array during the SMC event of February 17, 2015

\begin{tabular}{lllll}
\hline Site & $\mathrm{a}$ & $\mathrm{b}$ & $\mathrm{r}$ & $\sigma$ \\
\hline Salluit & 14.1 & 0.634 & 0.822 & 21.5 \\
Akulivik & 14.8 & 0.680 & 0.877 & 27.0 \\
Puvirnituq & 17.3 & 0.990 & 0.952 & 20.0 \\
Inukjuak & 5.40 & 1.107 & 0.957 & 23.4 \\
Radisson & 6.98 & 0.843 & 0.883 & 25.9 \\
\hline
\end{tabular}

and corresponding magnetic fields on the ground and in space (McPherron et al. 1973). The classic manifestation of this is an auroral zone westward electrojet with subauroral $+Y$ perturbations west of its central meridian and $-Y$ east of it. In Fig. 9 we show these features, the $B_{X}$ perturbation of an electrojet at NRCan station Fort Churchill, west of the AUTUMNX meridian by about two hours of magnetic local time, and paired subauroral $B_{Y}$ perturbations from AUTUMNX outlying station Saint-Félicien to the east and THEMIS GEONS station Ukia in the western USA. We thus claim that during the short (approximately $40 \mathrm{~min}$ ) period that these perturbations were extant, a substorm current wedge existed.

A further classic piece of evidence for a substorm is a dipolarization at geosynchronous orbit. Figure 10 shows the magnetic field measured with the Number 1 magnetometer of GOES 13, conjugate to AUTUMNX. In local spacecraft coordinates, the Hp component points toward the north pole, the He component Earthward, and the Hn component eastward. On a quiet day (February 13, 2015: data not shown) Hp displays a sinusoid-like variation with 


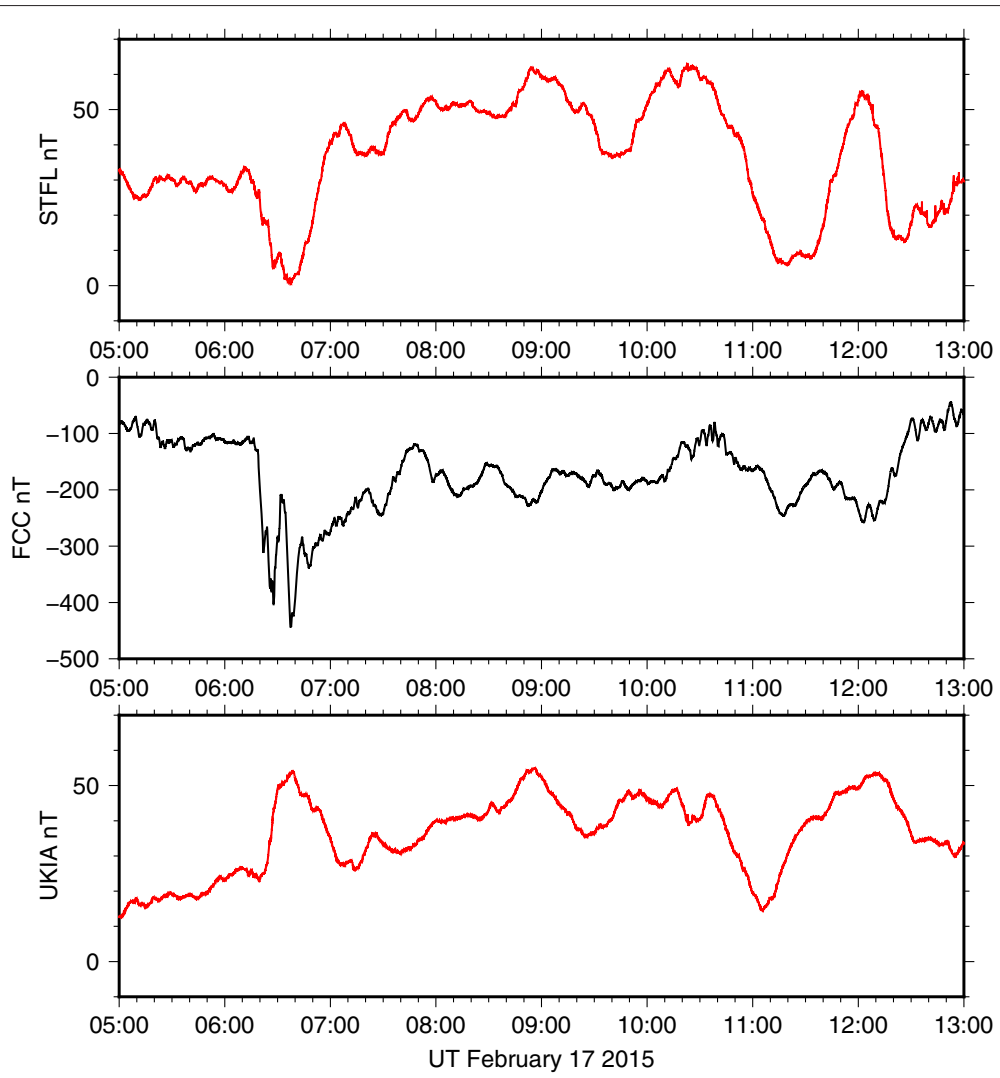

Fig. 9 Observations relevant to interpretation of a substorm-SMC connection for the event of February 17, 2015. The bottom and top panels show the $B_{Y}$ component at locations west and east of the inferred central meridian of a substorm that took place between 6 and 7 UT. The middle panel shows the $B_{X}$ component (relative to the value at the start of the day) at NRCan station Fort Churchill, inferred to be near the center of the substorm current wedge

minimum about $70 \mathrm{nT}$ about $3 \mathrm{UT}$ when the spacecraft is close to midnight, and a maximum of about $110 \mathrm{nT}$ close to noon, with He changing little (note that the Hp results are similar to those found in the statistical study of Jackel et al. (2012)). These values give a magnetic field inclination (middle panel) of about $60^{\circ}$ when near midnight and influenced by cross-tail currents, and about $80^{\circ}$ when near noon and influenced by dayside compression. By comparison, the value of inclination calculated as arctangent $(\mathrm{Hp} / \mathrm{He})$ was between 20 and $40^{\circ}$ until about 6 UT, a highly stretched condition. At the substorm onset time of 6:20 UT shown by AFM (Fig. 7), there was a large dipolarization, mainly due to an increase in the $\mathrm{Hp}$ component, and back to nearly the nominal $60^{\circ}$ inclination. The station at Inukjuak started a steady decrease in $B_{X}$ component at 6:15 UT, slightly before the GOES dipolarization.

We have illustrated the utility of doing a magnetic inversion to reduce a set of magnetograms in a meridian to physical parameters of a simple electrojet model. Verification that the parameters allow a good representation of the data is done by inspection of model results as compared to data. Where they did not match well, we inferred that another physical process than the dominant steady magnetic convection acted. It was demonstrated that this was a substorm. There appeared to be slight discrepancies between the time of onset of the substorm determined directly from ground magnetograms and from inversion. This timing question may be able to be answered in further studies now that we have a magnetic meridian chain constantly conjugate to a GOES satellite.

\section{Impulsive event of February 17, 2015}

Inspection of magnetogram summary plots of Fig. 6 led to the conclusion that a large impulsive change in the ground magnetic field took place at about 23:30 UT on February 17, 2015 (MLT approximately 18h). A similar impulsive change is visible in the conjugate GOES data of Fig. 10, with an inclination change similar to that of a dipolarization. We now examine in detail this impulsive change, whose large $\mathrm{dB} / \mathrm{dt}$ caused transformer harmonics in the Hydro-Québec power grid (S. Guillon, private communication, 2015). 


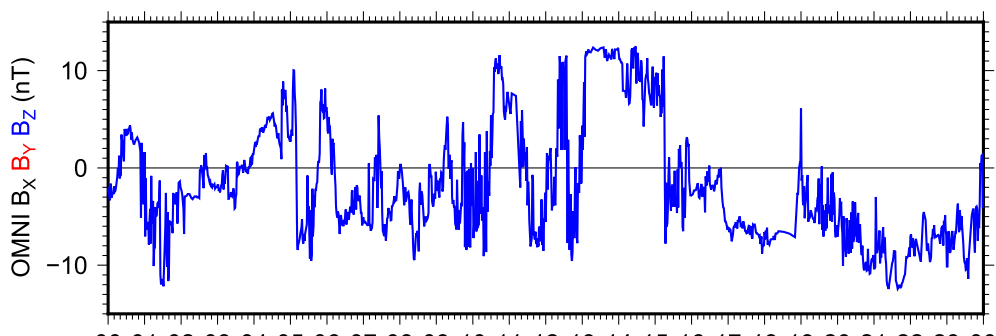

00010203040506070809101112131415161718192021222300
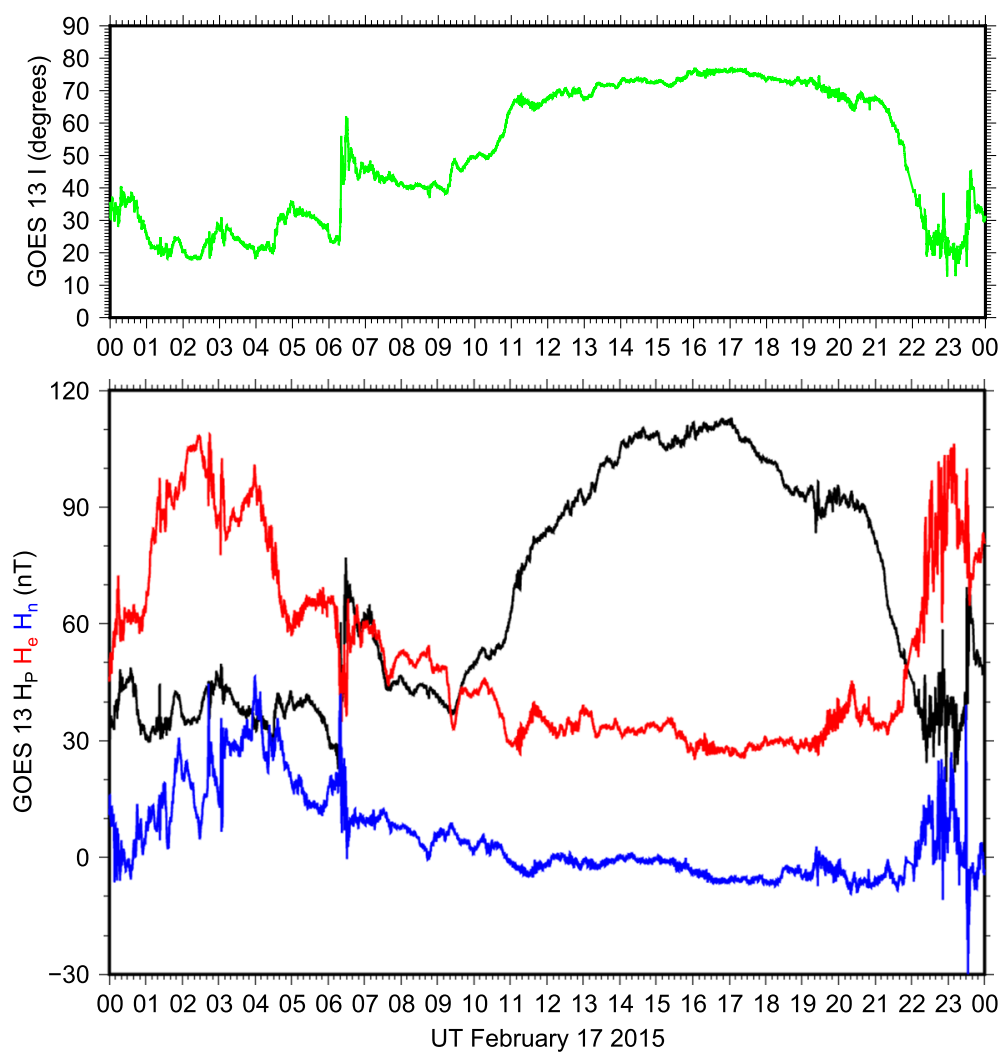

Fig. 10 GOES 13 magnetic field indicators and IMF $B_{Z}$ for the day of February 17, 2015. The bottom panel shows the $H_{p}$ (northward), $H_{e}$ (Earthward), and $H_{n}$ (eastward) components of the magnetic field at GOES. The middle panel shows the magnetic field inclination at GOES. The top panel shows the $B_{Z}$ component of IMF from the OMNI database

Figure 11 shows data from the last three hours of February 17, 2015 from AUTUMNX stations Radisson and Inukjuak, and NRCan station Sanikiluaq, spanning approximately $5^{\circ}$ in the auroral zone (note that Sanikiluaq is between the AUTUMNX stations, and slightly to the west). Data from the conjugate GOES 13 satellite is shown in local satellite coordinates. The THEMIS B satellite was upwind in the solar wind (THEMIS C data from a nearby location near the Moon as part of the ARTEMIS mission was similar and is not shown) in a good place (GSE $55,18,3$ in $\mathrm{R}_{E}$ units) to be a solar wind monitor for the event. At 22:00 UT, the solar wind speed had increased to $450 \mathrm{~km} / \mathrm{s}$ from $400 \mathrm{~km} / \mathrm{s}$ according to preliminary OMNI data. This means that a time delay of $11 \mathrm{~min}$ is needed to propagate comoving features in THEMIS B data to the magnetopause, assumed to be about $10 \mathrm{R}_{E}$ in front of Earth. This timeshift has been applied to THEMIS B data displayed.

To place the impulsive event in context, note the development of $B_{X}$ perturbation approaching $200 \mathrm{nT}$ at Radisson after approximately 22:00 UT. This represents growth of an evening sector eastward electrojet at low latitude. The accompanying $-B_{Z}$ perturbation suggests that the electrojet center was south of Radisson. Over $5^{\circ}$ south of Radisson, Val d'Or (VLDR) and Saint-Félicien (STFL) recorded an increase in $B_{Z}$ and $B_{X}$ (see Fig. 6, bottom), consistent with the growth of an eastward electrojet to their north. After 22:20 UT, GOES 13 showed irregular 


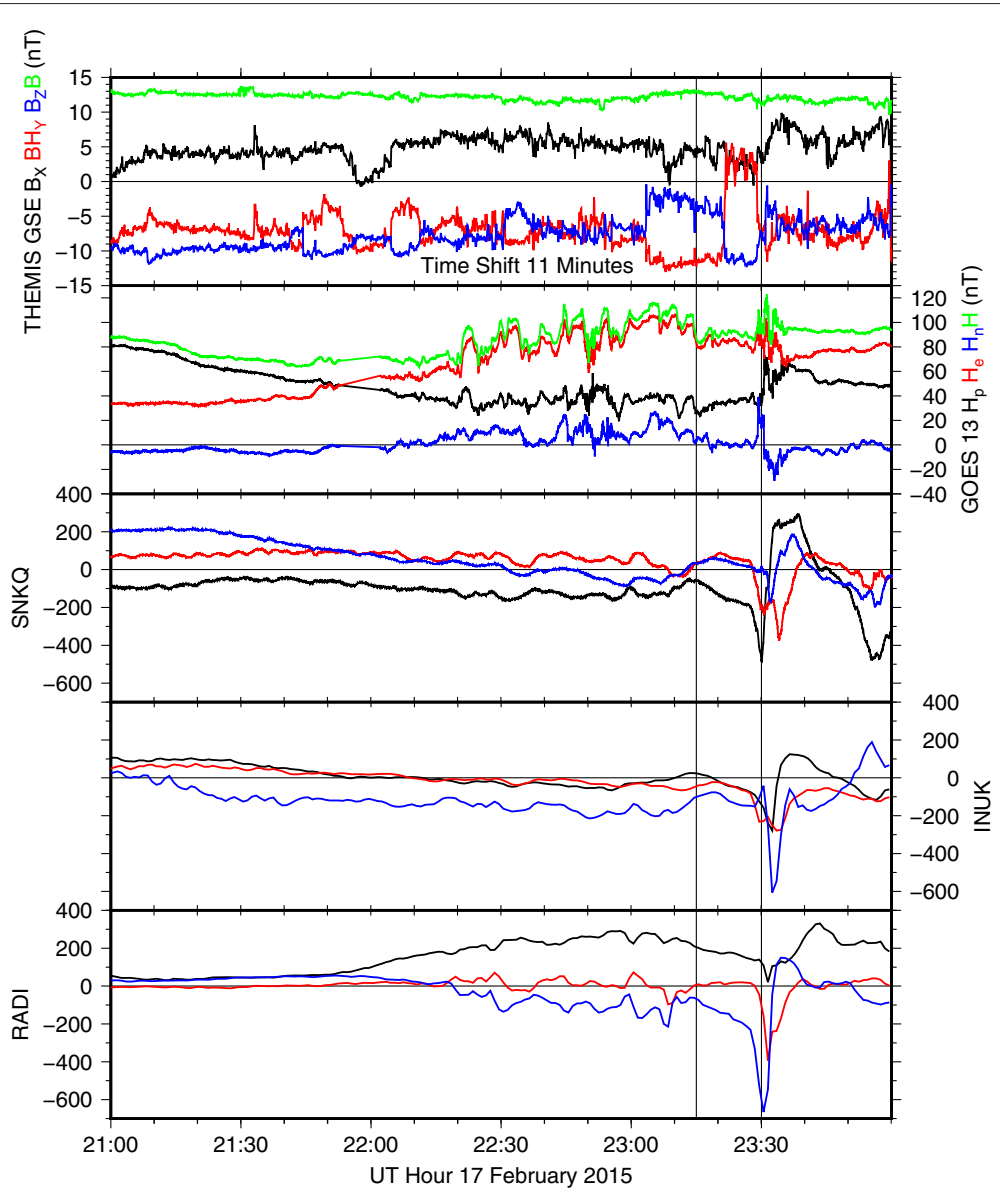

Fig. 11 Ground and space magnetic fields at the time near an impulsive event on February 17, 2015. The bottom panels show the three components ( $B_{X}$ in black, $B_{Y}$ in red, $B_{Z}$ in blue) of baselined data for AUTUMNX stations RADI and INUK, and NRCan station SNKQ relative to the starting value of the day. The second from top panel shows GOES 13 data in the same manner as Fig. 10 except that the total field has been added in green. The top panel shows the propagated (see text) solar wind magnetic field in GSE coordinates ( $B_{X}$ black, $B_{Y}$ red, $B_{Z}$ blue), with total field in green

changes on a growing magnetic field. Since the total field $(\mathrm{H}$ : green in the plot) changed, these seem to have been compressional in nature, although no clear pressure pulses were visible in the solar wind. These irregular changes also characterized the magnetic field on the ground during this period, as especially evident in the $B_{Z}$ component at Radisson. GOES particle data also showed irregular variations during this period, and a dropout of $4 \mathrm{MeV}$ electrons (data not shown). At 23:15 there was a particle recovery at GOES similar to an injection, and THEMIS $\mathrm{AE}$ increased. This time is marked by a vertical line in Fig. 11, and a decrease in the amplitude of irregular pulsations at GOES took place. Further, decreases in $B_{X}$ took place at the AUTUMNX stations shown. At Radisson, a decrease in $B_{Z}$ at the same time suggests the electrojet moved further south of the station. This is further backed up by yet stronger increases in $B_{X}$ and $B_{Z}$ at VLDR and STFL seen in Fig. 6 . These were presumably responses to either the step-like rotations $(\mathrm{H}$, green in plot panel, was near-constant, suggesting an Alfvénic nature for the changes) in solar wind B that arrived at 23:03 UT, or to a small impulsive change very near 23:15 UT. At approximately 23:28 UT, the $B_{Z}$ component at Radisson started to descend rapidly, followed by the $B_{X}$ component at Sanikiluaq and the $B_{Y}$ component at all three stations shown. Minima in $B_{X}$ at Sanikiluaq and $B_{Z}$ at Radisson were very shortly after $23: 30 \mathrm{UT}$, and an approximately 3 minute long spike of $40 \mathrm{nT}$ amplitude in the eastward component (Hn) at GOES was centered on this time. We regard 23:30 UT as the nominal time of the impulse, and this time is marked by a vertical line.

With the developments in the eastward electrojet underway, a major rotation (note that $|\mathrm{B}|$ was constant) in the solar wind magnetic field arrived essentially at the time of the impulse observed on the ground. This seems a short delay for propagation of expected solar wind effects, for example through the Dungey cycle (Cowley 2000), (Zhang et al. 2015), yet the low latitude seems to speak against more direct effects such as those possible near the cusp. The possible error in timing does support the idea 
that the rotation, in the form of a $+\mathrm{Y}$ change of $15 \mathrm{nT}$ and $-\mathrm{Z}$ of about $10 \mathrm{nT}$, was causative. This is backed up by a rough timing calculation based on a similar rotation seen at the ACE solar wind monitor at the inner Lagrange point from approximately 22:25 to 22:35 UT: the timing to THEMIS B's distance suggests a slightly earlier arrival at the magnetopause than we roughly determined. Dayside magnetic field changes were seen at Fresno CA (data not shown) starting at 23:20 with $+B_{X}$ and $-B_{Y}$ changes of each about $15 \mathrm{nT}$. This also suggests a slightly earlier arrival time. Since the changes were Alfvénic in nature, it is possible that wave propagation effects must be taken into account in determining an exact arrival time. The solar wind is generally super-Alfvénic near Earth, as backed up by a direct calculation of the Alfvén speed being $100 \mathrm{~km} / \mathrm{s}$, and OMNI's indicated Alfvén Mach number of about 5, so we conclude that such effects should be small. Without looking at causality, Jackel et al. (2012) found that for a large set of solar wind pressure changes, effects are felt at geosynchronous orbit within minutes of magnetopause impact. In our single case we can only say that unusual changes in the solar wind were observed essentially simultaneosly with unusual changes on the ground. With more fortuitous placement of spacecraft in other cases, we may be able to reach a time measuring threshhold to definitely establish causality for other impulse events, of which we have already detected many in the few months that AUTUMNX has operated.

This impulsive event, with large changes in the magnetic field on short timescales, produced large $\mathrm{dB} / \mathrm{dt}$ values. Consistent with what is shown in Fig. 11, NRCan calculated the $\mathrm{dB} / \mathrm{dt}$ at Sanikiluaq to be between -200 and +500 $\mathrm{nT} / \mathrm{min}$ ( 3 to $8 \mathrm{nT} / \mathrm{s}$ ) with the negative and then positive changes in the northward component. The rate of change in $B_{Z}$ at Radisson and Inukjuak would be comparable or larger. NRCan calculates that at Sanikiluaq, ground electric fields of Ex in the range -0.5 to $+0.2 \mathrm{~V} / \mathrm{km}$ and of Ey in the range +0.5 to $-0.7 \mathrm{~V} / \mathrm{km}$ would have been induced. While not extreme values, these electric fields appear to have induced GIC effects in transformers leading to generation of harmonics in the power grid. Monitoring data provided by Hydro-Québec (S. Guillon, private communication, 2015) indicates Total Harmonic Distortion (the sum of power in harmonics of $60 \mathrm{~Hz}$ ) having spiked sharply at 23:30 UT at $0.6 \%$ near Radisson, near the major La Grande 2 hydroelectric generating site. Lesser levels of up to $0.38 \%$ were detected near Montréal (a major city close to Ottawa in Fig. 4, in a power consumption/distribution area), but elevated levels persisted over about one hour. None of these GIC had any operational impact on the power system as it is presently configured.

In summary, we have connected an impulsive change in the geomagnetic field detected by the AUTUMNX array to changes observed at the GOES conjugate satellite and linked them to a large rotational solar wind magnetic field change. These unusual changes came while the eastward electrojet was active and at low latitude on a geomagnetically active day. Harmonic distortion was observed in the local power system with largest values near where AUTUMNX measured the maximum dB/dt. Boteler (2001) noted that the March 13, 1989 power failure in eastern North America, and more specifically transformer damage at low latitudes, appeared to be associated with activity of the eastward electrojet. The more southerly stations of AUTUMNX allow us to monitor geomagnetic activity in the vicinity of the major electrical generating and distribution facilities of Hydro-Québec in a region geologically susceptible to GIC development.

\section{Conclusions}

We have described the current situation of magnetometer stations on a world scale. Despite their relatively large number, AUTUMNX, spanning the auroral zone in eastern Canada, has an important role to play. Present ground conjugacy opportunities are poor, but with further activity in Antarctica we hope to take advantage of the unique opportunities AUTUMNX offers for such studies. We discussed AUTUMNX hardware and ways to effect low power reliable operation making near real time data available on the internet. We stressed that AUTUMNX is in a region having important energy generation and transmission facilities in a geological setting which makes them vulnerable to GIC. An example of a large $d B / d t$ event was discussed with the conclusion that it took place near a growing evening sector eastward electrojet at low latitude and was triggered by an unusual magnetic rotation in the solar wind. This impulsive event was detected on the ground and at the conjugate GOES East spacecraft at the same time as GIC-related harmonic distortion in the power grid. We applied the AFM analysis technique to successfully reduce the behavior of a steady magnetic convection event to three simple parameters, which appeared to have a relationship to the $B_{Z}$ component of the solar wind.

AUTUMNX data will now be available to the space physics community to permit further such studies to advance both basic science and space weather studies.

\section{Endnote}

${ }^{1}$ Note that Sanikiluaq is the NRCan replacement observatory for Poste de la Baleine (PBQ: in turn historically known as Great Whale River, GWR) in the Canadian national observatory program, and contributes to the AE index. The AUTUMNX site at Kuujuarapik is near the former site of the NRCan observatory PBQ. 


\section{Abbreviations}

AFM: Automated forward modeling; AFM: Automated meridian modeling; AUTUMN: Athabasca University THEMIS UCLA Magnetometer Network; AUTUMNX: Athabasca University THEMIS UCLA Magnetometer Network eXtension; BAS: British antarctic survey; $B_{X}, B_{Y}, B_{Z}$ (ground): northward, eastward, and downward magnetic field perturbations, here in local magnetic coordinates; $B_{X}, B_{Y}, B_{Z}$ (space): sunward, prograde, and toward north ecliptic pole magnetic field components, in GSE or GSM coordinates as specified; CANMOS: CANadian magnetic observatory system (of NRCan); CARISMA: Canadian array for realtime investigations of magnetic activity; CGM: Corrected geomagnetic (Coordinates); EHB: East Hudson Bay; GEONS: Geomagnetic Event observation network by students; GIC: Geomagnetically induced currents; GOES: Geostationary operational environmental satellite; $H_{p}, H_{e}, H_{n}$ : (GOES spacecraft) roughly northward, Earthward, and eastward spacecraft local magnetic field components; MACCS: Magnetometer Array for Cleft and Cusp Studies; NRCan - Natural Resources Canada; RE: Earth radius; SCW: Substorm current wedge; SMC: Steady magnetospheric convection; STEP: Solar-Terrestrial energy program; THEMIS: Time history of events and macroscale interactions during Substorms; $X, Y, Z$ : GSE or GSM coordinates in $R_{E} ;$ UCLA: University of California, Los Angeles; UI: user interface.

\section{Competing interests}

The authors declare no competing interests.

\section{Authors' contributions}

MC organized the article, did analysis, and is the PI of AUTUMN and AUTUMNX. IS and KR provided technical support and analysis. PC and CR are co-Is of AUTUMNX and provided information about PRIMO. MC, CR, KMR, IS, and KR developed AUTUMNX instrumentation, installed by IS, MC, and KR. All authors read and approved the final manuscript.

\section{Acknowledgements}

Establishment of AUTUMN was supported by the Canada Foundation for Innovation (CFI) and the Alberta ASRIP Program. Its operation is supported by IOF funds of the CFI. Establishment and operation of AUTUMNX are supported through the Geospace Observatory (GO) Canada initiative of the Canadian Space Agency. We thank Sébastien Guillon of Hydro-Québec for information about harmonic distortion measured in the network. We acknowledge NASA contract NAS5-02099 and V. Angelopoulos for use of data from the THEMIS Mission. We thank J.H. King and N. Papatashvilli for OMNI data, and N. Ness for preliminary ACE data, downloaded through CDAWeb, Howard Singer for GOES data, obtained through the National Geophysical Data Center, and Jesper Gjerloev for use of the SuperMAG site. MC thanks David Sibeck for useful comments about the setting for the impulsive event. We thank the Centre ditudes Nordiques, NRCan, and school boards and astronomy associations in Québec for hosting AUTUMNX sites.

\section{Author details}

${ }^{1}$ Athabasca University Observatories, 1 University Drive, Athabasca, AB T9S 3A3, Canada. ${ }^{2}$ IGPP, UCLA, Los Angeles, CA, USA.

\section{Received: 6 May 2015 Accepted: 4 November 2015}

Published: 7 January 2016

\section{References}

Akasofu S-I (1964) The Development of the Auroral Substorm. Planet Space Sci 12:273-282

Angelopoulos V (2008) The THEMIS Mission. Space Sci Rev 141:5-34. doi:10.1007/s11214-008-9336-1

Baker KB, Wing S (1989) A new magnetic coordinate system for conjugate studies at high latitudes. J Geophys Res 94:9139-9143

Birkeland K (1908) The Norwegian Aurora Polaris Expedition 1902-3, Part 1. A. Aschehoug, Christiania, Norway

Bolduc L (2002) GIC observations and studies in the Hydro-Québec power system. JASTP 64:17931802

Boteler DH (2001) Space weather effects on power systems, Space Weather Geophys Monogr Ser, Vol. 125(Song P, Singer HJ, Siscoe GL, eds.). AGU, Washington, DC

Chapman S, Bartels J (1940) Geomagnetism, Vol. II: Analysis of the Data, and Physical Theories. Oxford University Press, London
Chi PJ, Engebretson MJ, Moldwin MB, Russell CT, Mann IR, Hairston MR, et al (2013) Sounding of the plasmasphere by Mid-continent MAgnetoseismic Chain (McMAC) magnetometers. J. Geophys. Res 118:3077-3086. doi:10.1002/jgra.50274

Cliver EW (2005) The 1859 space weather event: Then and now. Adv. Sp. Res 38. doi:10.1016/j.asr.2005.07.077

Connors M, McPherron RL, Anderson B, Korth H, Russell CT, Chu X (2014) Electric Currents of a Substorm Current Wedge on 24 February 2010. Geophys. Res. Lett 41:4449-4455. doi:10.1002/2014GL060604

Connors M, Rostoker G (2015) Inverting Magnetic Meridian Data Using Nonlinear Optimization. Earth Planets Space 67:155. doi:10.1186/s40623-015-0315-y

Cowley S (2000) Magnetosphere-lonosphere Interactions: A Tutorial Review. In: Ohtani S-I, Fujii R, Hesse M, Lysak RL (eds). Magnetospheric Current Systems. American Geophysical Union, Washington

Gjerloev JW (2009) A Global Ground-Based Magnetometer Initiative. EOS 90:230-231. doi:10.1029/2009EO270002

Gjerloev, JW (2012) The SuperMAG data processing technique. J. Geophys. Res 117:A09213. doi:10.1029/2012JA017683

Gustafsson G (1984) Corrected geomagnetic coordinates for Epoch 1980. In: Potemra TA (ed). Magnetospheric currents. American Geophysical Union, Washington

Harris SE, Mende SB, Angelopoulos V, Rachelson W, Donovan E, Jackel B, et al (2008) THEMIS Ground Based Observatory System Design. Space Science Reviews 141:213-233. doi:10.1007/s11214-007-9294-z

Jackel BJ, McKiernan B, Singer HJ (2012) Geostationary magnetic field response to solar wind pressure variations: Time delay and local time variation. J. Geophys. Res 117:A05203. doi:10.1029/2011JA017210

Jackson A (1992) Historical data for geomagnetic field modelling. In: Langel RA, Baldwin RT (eds). Types and Characteristics of Data for Geomagnetic Field Modeling. NASA, Greenbelt MD

Jackson JD (1975) Classical Electrodynamics. John Wiley, New York

Kisabeth JL (1979) On Calculating Magnetic and Vector Potential Fields due to Large-Scale Magnetospheric Current Systems and Induced Currents in an Infinitely Conducting Earth. In: Olson WP (ed). Quantitative Modeling of Magnetospheric Processes. American Geophysical Union, Washington DC

Kisabeth JL, Rostoker G (1977) Modeling of the three-dimensional current systems associated with magnetospheric substorms. Geophys. J. R. astr. Soc 49:655-683

Kissinger J, McPherron RL, Hsu T-S, Angelopoulos V, Chu X (2012) Necessity of substorm expansions in the initiation of steady magnetospheric convection. Geophys. Res. Lett 39:L15105. doi:10.1029/2012GL052599

Lampton M (1997) Damping-undamping Strategies for the Levenberg-Marquardt Nonlinear Least Squares Method. Computers in Physics 11:110-115

(2014) Solar-Terrestrial Research in Polar Regions: Past, Present, and Future(Lessard MR, Gerrard AJ, Weatherwax AT, eds.). University of New Hampshire, Durham, $\mathrm{NH}$

Mann IR, Milling DK, Rae IJ, Ozeke LG, Kale A, Kale ZC, et al (2008) The upgraded CARISMA magnetometer array in the THEMIS era. Space Sci. Rev 141:413-451. doi:10.1007/s11214-008-9457-6

Mann IR, Voronkov I, Dunlop M, Donovan E, Yeoman TK, Milling DK, et al (2002) Coordinated ground-based and Cluster observations of large amplitude global magnetospheric oscillations during a fast solar wind speed interval. Ann. Geophys 20:405-426

McPherron RL, Russell CT, Aubry MP (1973) Satellite studies of magnetospheric substorms on August 15, 1968, 9. Phenomenological Model for Substorms. J Geophys Res 78:3131-3149

Motoba T, Ohtani S, Kadokura A, Gjerloev J (2014) Interrelationship between preonset auroral and magnetic signatures at a geomagnetically conjugate Iceland-Syowa pair. J. Geophys. Res 119:761-769. doi:10.1002/2013JA019512

NERC (2013) Geomagnetic Disturbance Planning Guide. North American Electric Reliability Corporation, Atlanta, GA

Nishimura Y, Lyons LR, Zou S, Xing X, Angelopoulos V, Mende SB, et al (2010) Preonset time sequence of auroral substorms: Coordinated observations by all-sky imagers, satellites, and radars. J Geophys Res 115:A00108. doi:10.1029/2010JA015832

Peticolas LM, Craig N, Odenwald SF, Walker A, Russell CT, Angelopoulos V, et al (2008) The Time History of Events and Macroscale Interactions during Substorms (THEMIS) Education and Outreach (E/PO) Program. Space Sci. Rev 141:557-583 
Potemra T (1985) Field-Aligned (Birkeland) Currents. Sp. Sci. Rev 42:295-311

Press WH, Teukolsky SA, Vetterling WT, Flannery BP (1992) Numerical Recipes in C. 2nd. Cambridge University Press, Cambridge

Russell CT, Chi PJ, Dearborn DJ, Ge YS, Kuo-Tiong B, Means JD, et al (2008) THEMIS ground-based magentometers. Space Sci. Rev 141:389-412. doi:10.1007/s11214-008-9337-0

SAMBA/AMBER Project (2013). http://magnetometers.bc.edu/index.php/ samba. Accessed 26 Oct 2015

Schofield I, Connors M, Russell CT (2012) NetPICOmag: A low-cost networked magnetometer and its applications. Earth, Planets Space 64:279-297

Shepherd SG (2014) Altitude-Adjusted Corrected Geomagnetic Coordinates: Definition and Functional Approximations. J. Geophys. Res 119. doi:10.1002/2014JA020264

Soffel HC (2015) History of the MunichMaisachFrstenfeldbruck Geomagnetic Observatory. Hist. Geo. Space Sci 6:6586. doi:10.5194/hgss-6-65-2015

Stern DP (2002) A Millenium of Geomagnetism. Rev. Geophys 40. B-1-B-30 doi:10.1029/2000RG000097

Surkan AJ, Lanzerotti LJ (1974) ULF geomagnetic power near L=4 3. Statistical study of power spectra in conjugate areas during December solstice. J. Geophys. Res 79:2403-2412

Tanskanen El (2009) A comprehensive high-throughput analysis of substorms observed by IMAGE magnetometer network: years 1993-2003 examined. J. Geophys. Res 114:A05204. doi:10.1029/2008JA013682

Tsyganenko NA (1989) A magnetospheric magnetic field model with a warped tail current sheet. Plan. Space Sci 37:5-20

Wang C (2010) New Chains of Space Weather Monitoring Stations in China. Space Weather 8:S08001. doi:10.1029/2010SW000603

Wei LH, Homeier N, Gannon JL (2013) Surface electric fields for North America during historical geomagnetic storms. Space Weather 11:451-462. doi:10.1002/swe.20073

Wescott EM (1966) Magnetoconjugate Phenomena. Space Science Reviews 5:507-561

Yumoto K (1996) $210^{\circ}$ MM Magnetic Observation Group 1996,The STEP $210^{\circ}$ Magnetic Meridian Network Project. J. Geomag. Geoelectr 48:1297-1309

Zhang Q-H, Lockwood M, Foster JC, Zhang S-R, Zhang B-C, McCrea IW, et al (2015) Direct observations of the full Dungey convection cycle in the polar ionosphere for southward interplanetary magnetic field conditions. J. Geophys. Res 120:45194530. doi:10.1002/2015JA021172

Ziesolleck CWS, Feng Q, McDiarmid DR (1996) Pc 5 ULF waves observed simultaneously by GOES 7 and the CANOPUS magnetometer array. J. Geophys. Res 101:5021-5034

\section{Submit your manuscript to a SpringerOpen ${ }^{\circ}$ journal and benefit from:}

- Convenient online submission

$\checkmark$ Rigorous peer review

- Immediate publication on acceptance

- Open access: articles freely available online

- High visibility within the field

- Retaining the copyright to your article

Submit your next manuscript at $\gg$ springeropen.com 